\title{
Urban organic aerosol composition in eastern China differs from north to south: molecular insight from a liquid chromatography-mass spectrometry (Orbitrap) study
}

\author{
Kai Wang ${ }^{1,2,5}$, Ru-Jin Huang ${ }^{1,3}$, Martin Brüggemann ${ }^{4}$, Yun Zhang ${ }^{2}$, Lu Yang ${ }^{1}$, Haiyan Ni ${ }^{1}$, Jie Guo ${ }^{1}$, Meng Wang ${ }^{1}$, \\ Jiajun Han ${ }^{6}$, Merete Bilde ${ }^{5}$, Marianne Glasius ${ }^{5}$, and Thorsten Hoffmann ${ }^{2}$ \\ ${ }^{1}$ State Key Laboratory of Loess and Quaternary Geology (SKLLQG), Center for Excellence in Quaternary Science and \\ Global Change, and Key Laboratory of Aerosol Chemistry and Physics, Institute of Earth and Environment, Chinese \\ Academy of Sciences, Xi' an 710061, China \\ ${ }^{2}$ Institute of Inorganic and Analytical Chemistry, Johannes Gutenberg University Mainz, \\ Duesbergweg 10-14, Mainz 55128, Germany \\ ${ }^{3}$ Open Studio for Oceanic-Continental Climate and Environment Changes, Pilot National Laboratory for Marine Science \\ and Technology (Qingdao), Qingdao 266061, China \\ ${ }^{4}$ Atmospheric Chemistry Department (ACD), Leibniz Institute for Tropospheric Research (TROPOS), \\ Permoserstraße 15, 04318 Leipzig, Germany \\ ${ }^{5}$ Department of Chemistry, Aarhus University, Langelandsgade 140, 8000 Aarhus C, Denmark \\ ${ }^{6}$ Department of Chemistry, University of Toronto, 80 St. George Street, M5S3H6 Toronto, Canada
}

Correspondence: Ru-Jin Huang (rujin.huang@ieecas.cn) and Thorsten Hoffmann (t.hoffmann@uni-mainz.de)

Received: 8 October 2019 - Discussion started: 11 November 2019

Revised: 18 May 2020 - Accepted: 4 June 2020 - Published: 15 June 2021

\begin{abstract}
Air pollution by particulate matter in China affects human health, the ecosystem and the climate. However, the chemical composition of particulate aerosol, especially of the organic fraction, is still not well understood. In this study, particulate aerosol samples with a diameter of $\leq 2.5 \mu \mathrm{m}$ $\left(\mathrm{PM}_{2.5}\right)$ were collected in January 2014 in three cities located in northeast, east and southeast China, namely Changchun, Shanghai and Guangzhou. Organic aerosol (OA) in the $\mathrm{PM}_{2.5}$ samples was analyzed by an ultrahigh-performance liquid chromatograph (UHPLC) coupled to a high-resolution Orbitrap mass spectrometer in both negative mode (ESI-) and positive mode electrospray ionization (ESI+). After nontarget screening including the assignment of molecular formulas, the compounds were classified into five groups based on their elemental composition, i.e., $\mathrm{CHO}, \mathrm{CHON}, \mathrm{CHN}$, $\mathrm{CHOS}$ and $\mathrm{CHONS}$. The $\mathrm{CHO}, \mathrm{CHON}$ and $\mathrm{CHN}$ groups present the dominant signal abundances of $81 \%-99.7 \%$ in the mass spectra and the majority of these compounds were assigned to mono- and polyaromatics, suggesting that anthropogenic emissions are a major source of urban OA in all
\end{abstract}

three cities. However, the chemical characteristics of these compounds varied between the different cities. The degree of aromaticity and the number of polyaromatic compounds were substantially higher in samples from Changchun, which could be attributed to the large emissions from residential heating (i.e., coal combustion) during wintertime in northeast China. Moreover, the ESI- analysis showed higher $\mathrm{H} / \mathrm{C}$ and $\mathrm{O} / \mathrm{C}$ ratios for organic compounds in Shanghai and Guangzhou compared to samples from Changchun, indicating that OA undergoes more intense photochemical oxidation processes in lower-latitude regions of China and/or is affected to a larger degree by biogenic sources. The majority of sulfur-containing compounds (CHOS and CHONS) in all cities were assigned to aliphatic compounds with low degrees of unsaturation and aromaticity. Here again, samples from Shanghai and Guangzhou show a greater chemical similarity but differ largely from those from Changchun. It should be noted that the conclusions drawn in this study are mainly based on comparison of molecular formulas weighted by peak abundance and thus are associated with inherent uncer- 
tainties due to different ionization efficiencies for different organic species.

\section{Introduction}

In the last decades, China has experienced rapid industrialization and urbanization accompanied by severe and persistent particulate air pollution (Huang et al., 2014; Sun et al., 2014; Ding et al., 2016; Song et al., 2018; Shi et al., 2019; Xu et al., 2019). These particulate air pollution extremes can not only influence the regional air quality and human health in China, but also lead to a global environmental problem due to long-distance transport of pollutants. To better understand the effects of air pollution on air quality and human health, chemical characterization of fine particles (particulate matter with an aerodynamic diameter of less than $2.5 \mu \mathrm{m}$, or $\mathrm{PM}_{2.5}$ ) is crucial. However, the chemical composition of $\mathrm{PM}_{2.5}$ in China is still poorly understood due to a wide variety of natural and anthropogenic sources as well as complex multiphase chemical reactions (Lin et al., 2012a; Huang et al., 2014; Ding et al., 2016; Wang et al., 2017, 2018, 2019a, b; An et al., 2019; Tong et al., 2019). In particular, compared to the fairly well understood nature of the inorganic fraction of aerosol, the organic fraction, also named organic aerosol (OA), is considerably less understood in terms of chemical composition, corresponding precursors, sources and formation mechanisms (Huang et al., 2017).

During pollution events in China, OA accounts for as high as more than $50 \%$ of the total mass of fine particles (An et al., 2019). Chemical compounds in OA cover a large complexity of species including alcohols, aldehydes, carboxylic acids, imidazoles, organosulfates, organonitrates and polycyclic aromatic hydrocarbons (PAHs) (Lin et al., 2012a; Rincón et al., 2012; Kourtchev et al., 2014; Wang et al., 2018, 2019a; Elzein et al., 2019). Thus, the capacity of traditional analytical techniques is limited to identify the compounds in $\mathrm{OA}$, and the majority ( $>70 \%$ ) of OA has not been identified yet as specific compounds (Hoffmann et al., 2011). The insufficient knowledge of chemical composition of OA hinders a better understanding of the sources, formation and atmospheric processes of air pollution in China.

Recently, ultrahigh-resolution mass spectrometry (UHRMS), such as Fourier transform ion cyclotron resonance mass spectrometry (FTICR-MS) and the Orbitrap MS, coupled with soft ionization sources (e.g., electrospray ionization, ESI, and atmospheric pressure chemical ionization, APCI), has been introduced to elucidate the molecular composition of OA (Nizkorodov et al., 2011; Lin et al., 2012a, b; Rincón et al., 2012; Noziere et al., 2015; Kourtchev et al., 2016; Tong et al., 2016; Tu et al., 2016; Brüggemann et al., 2017, 2019; Wang et al., 2017, 2018, 2019a; Fleming et al., 2018; Laskin et al., 2018; Song et al., 2018; Daellenbach et al., 2019; Ning et al., 2019). Due to the two outstanding features of high resolving power and high mass accuracy, UHRMS can give precise elemental compositions of individual organic compounds. However, UHRMS studies on Chinese urban OA are very limited. Wang et al. (2017) characterized OA in Shanghai and showed variations in chemical composition among different months and between daytime and nighttime. Our recent Orbitrap MS study (Wang et al., 2018) showed that wintertime OA in $\mathrm{PM}_{2.5}$ collected in Beijing, China, and Mainz, Germany, was very different in terms of chemical composition. In contrast, for summertime OA from Germany and China, Brüggemann et al. (2019) found similar compounds and concentrations of terpenoid organosulfates in $\mathrm{PM}_{10}$, demonstrating that biogenic emission can significantly affect OA composition at both locations. Ning et al. (2019) analyzed the OA collected in a coastal Chinese city (Dalian) and found that more organic compounds were identified on haze days compared to non-haze days. Nonetheless, since severe particulate pollution in China occurs on a large scale, more UHRMS studies are needed to fully elucidate the chemical composition of OA in different Chinese cities.

In this study, $\mathrm{PM}_{2.5}$ aerosol samples were collected in three Chinese cities, i.e., Changchun, Shanghai and Guangzhou, and their organic fraction was analyzed using an ultra-high-performance liquid chromatograph (UHPLC) coupled with an Orbitrap MS. The Chinese cities of Changchun, Shanghai and Guangzhou are located in the northeast, east and southeast of China, which are major populated regions in China with populations of 7.5, 24 and 15 million, respectively. The geographic locations of these three cities cover a large latitude spanning from 23.12 to $43.53^{\circ} \mathrm{N}$, resulting in different meteorological conditions, including intensity and duration of sunlight, average daily temperature, and monsoon climate. In addition, the industrial structure, energy consumption and energy sources in these three cities are different; for example there is much more heavy industry (e.g., coal chemical industry and steelworks) in northeast China (Zhang, 2008), which can cause difference in anthropogenic emissions and can therefore influence the chemical composition of urban OA. Moreover, OA is strongly affected by residential coal combustion during winter in northeast China (Huang et al., 2014; An et al., 2019). Therefore, this study presents a comprehensive overview of chemical composition of OA in three representative Chinese cities during pollution episodes, which eventually can improve our understanding of OA effects on climate and public health and also provide a chemical database for haze mitigation strategies in China. 

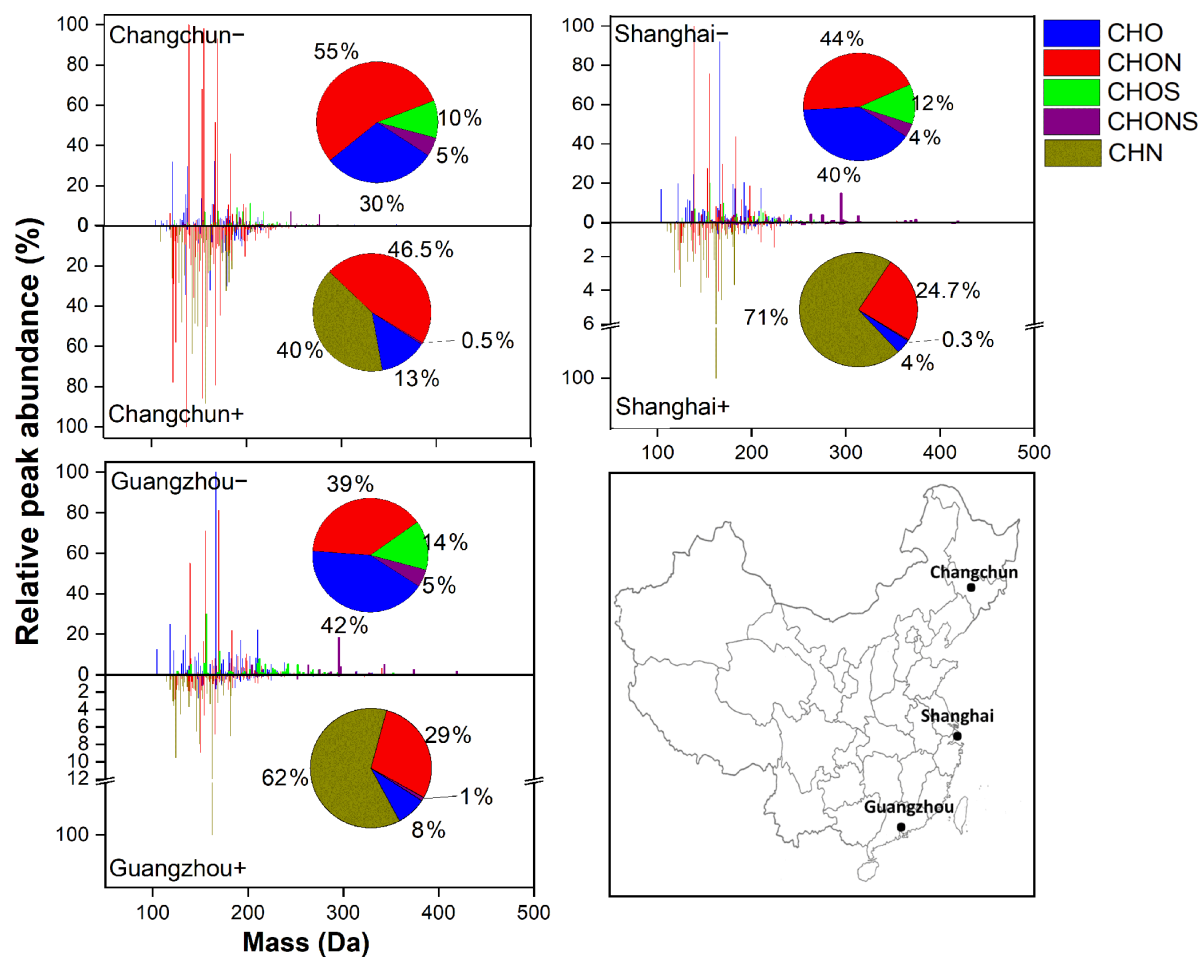

Figure 1. Mass spectra of detected organic compounds reconstructed from extracted ion chromatograms in ESI- and ESI+. The horizontal axis refers to the molecular mass (Da) of the identified species. The vertical axis refers to the relative peak abundance of each individual compound compared to the compound with the greatest peak abundance. The pie charts show the percentage of each organic compound subgroup (i.e., $\mathrm{CHO}, \mathrm{CHON}, \mathrm{CHOS}, \mathrm{CHONS}$ and $\mathrm{CHN}$ ) in each sample in terms of peak abundance. The map in the lower right corner shows the locations of these three megacities in China.

\section{Experimental}

\section{1 $\quad \mathbf{P M}_{2.5}$ samples}

Three $24 \mathrm{~h}$ integrated urban $\mathrm{PM}_{2.5}$ samples were collected during severe haze pollution events with daily average $\mathrm{PM}_{2.5}$ mass concentration higher than $115 \mu \mathrm{g} \mathrm{m}^{-3}$ in each of the three Chinese cities: Changchun $\left(43.54^{\circ} \mathrm{N}, 125.13^{\circ} \mathrm{E}, 1.5 \mathrm{~m}\right.$ above the ground), Shanghai $\left(31.30^{\circ} \mathrm{N}, 121.50^{\circ} \mathrm{E}, 20 \mathrm{~m}\right.$ above the ground) and Guangzhou $\left(23.07^{\circ} \mathrm{N}, 113.21^{\circ} \mathrm{E}\right.$, $53 \mathrm{~m}$ above the ground), which are located in the northeast, east and southeast regions of China, respectively (see Fig. 1). Samples in Changchun were collected on 4, 24 and 29 of January 2014 with $\mathrm{PM}_{2.5}$ mass concentrations of 185 $222 \mathrm{\mu g} \mathrm{m}^{-3}$; samples in Shanghai were collected on 1, 19 and 20 of January 2014 with $\mathrm{PM}_{2.5}$ mass concentrations of 159$172 \mu \mathrm{g} \mathrm{m}^{-3}$; and samples in Guangzhou were collected on 5, 6 and 11 of January 2014 with $\mathrm{PM}_{2.5}$ mass concentrations of $138-152 \mu \mathrm{g} \mathrm{m}^{-3}$. Further details (e.g., the daily average concentrations of $\mathrm{PM}_{2.5}, \mathrm{SO}_{2}, \mathrm{NO}_{2}, \mathrm{CO}$ and $\mathrm{O}_{3}$, the average temperature, and the daily solar radiation value during sampling dates) are presented in Table S1, and the $48 \mathrm{~h}$ back trajectories of air arriving at the three sampling sites during the sampling periods are shown in Fig. S1 in the Supplement. All $\mathrm{PM}_{2.5}$ samples were collected on prebaked quartz-fiber filters
$(20.3 \mathrm{~cm} \times 25.4 \mathrm{~cm})$ using a high-volume $\mathrm{PM}_{2.5}$ sampler at a flow rate of $1.05 \mathrm{~m}^{3} \mathrm{~min}^{-1}$ (Tisch Environmental, USA) and at each sampling site field blanks were taken. After sample collection, filters were stored at $-20^{\circ} \mathrm{C}$ until analysis.

\subsection{Sample analysis}

A detailed description of the filter sample extraction and UHPLC-Orbitrap MS analysis can be found in our previous studies (Wang et al., 2018, 2019a). Briefly, a part of the filters (around $1.13 \mathrm{~cm}^{2}$, corresponding to about $600 \mu \mathrm{g}$ particle mass in each extracted filter) was extracted three times with $1.0-1.5 \mathrm{~mL}$ of acetonitrile water $(8 / 2, v / v)$ in an ultrasonic bath. The extracts were combined, filtered through a $0.2 \mu \mathrm{m}$ Teflon syringe filter and evaporated to almost dryness under a gentle nitrogen stream. Finally, the residue was redissolved in $1000 \mu \mathrm{L}$ acetonitrile water $(1 / 9, v / v)$ to reach the total particulate mass concentration of around $600 \mu \mathrm{g} \mathrm{mL}^{-1}$ for the following analysis.

Compared to the direct infusion method applied in other UHRMS studies (Lin et al., 2012a, b; Rincón et al., 2012; Kourtchev et al., 2016; Fleming et al., 2018), the UHPLC technique was used in this study, which could separate and concentrate the compounds before they entered the ion source, reducing the ionization suppression and increasing 
the sensitivity of the measurement. In addition, it can provide separation of some compounds and information of retention time of the compounds, which is useful for the identification of the compounds and the separation of isomers. The analytes were separated using a Hypersil GOLD column $(\mathrm{C} 18,50 \times 2.0 \mathrm{~mm}, 1.9 \mu \mathrm{m}$ particle size $)$ with mobile phases consisting of (A) $0.04 \%$ formic acid and $2 \%$ acetonitrile in Milli-Q water and (B) $2 \%$ water in acetonitrile. Gradient elution was applied with the A and B mixture at a flow rate of $500 \mu \mathrm{L} \mathrm{min}^{-1}$ as follows: $0-1.5 \mathrm{~min} 2 \% \mathrm{~B}, 1.5-$ $2.5 \mathrm{~min}$ from $2 \%$ to $20 \% \mathrm{~B}$ (linear), $2.5-5.5 \mathrm{~min} 20 \% \mathrm{~B}$, 5.5-6.5 min from $20 \%$ to $30 \%$ B (linear), $6.5-7.5 \mathrm{~min}$ from $30 \%$ to $50 \%$ B (linear), $7.5-8.5$ min from $50 \%$ to $98 \%$ B (linear), $8.5-11.0 \mathrm{~min} 98 \% \mathrm{~B}, 11.0-11.05 \mathrm{~min}$ from $98 \%$ to $2 \% \mathrm{~B}$ (linear), and $11.05-11.1 \mathrm{~min} 2 \% \mathrm{~B}$. The Q Exactive hybrid quadrupole-Orbitrap MS was equipped with a heated ESI source at $120^{\circ} \mathrm{C}$, applying a spray voltage of $-3.3 \mathrm{kV}$ and $4.0 \mathrm{kV}$ for negative ESI mode (ESI-) and positive ESI mode (ESI+), respectively. The mass scanning range was set from $\mathrm{m} / z 50$ to 500 with a resolving power of 70000 $m / z$ 200. The Orbitrap MS was externally calibrated before each measurement sequence using an Ultramark 1621 solution (Sigma-Aldrich, Germany) providing mass accuracy of the instrument lower than $3 \mathrm{ppm}$. Each sample was measured in triplicate with an injection volume of $10 \mu \mathrm{L}$.

\subsection{Data processing}

A non-target peak picking software (SIEVE ${ }^{\circledR}$, Thermo Fisher Scientific, Germany) was used to find significant peaks in the LC-MS dataset and to calculate all mathematically possible chemical formulas for ion signals with a sample-to-blank abundance ratio $\geq 10$ using a mass tolerance of $\pm 2 \mathrm{ppm}$. The permitted maximum elemental number of atoms was set as follows: ${ }^{12} \mathrm{C}(39),{ }^{1} \mathrm{H}(72),{ }^{16} \mathrm{O}(20),{ }^{14} \mathrm{~N}(7),{ }^{32} \mathrm{~S}(4)$, ${ }^{35} \mathrm{Cl}$ (2) and ${ }^{23} \mathrm{Na}$ (1) (Kind and Fiehn, 2007; Lin et al., 2012a; Wang et al., 2018). To remove the chemically unreasonable formulas, further constraint was applied by setting $\mathrm{H} / \mathrm{C}, \mathrm{O} / \mathrm{C}, \mathrm{N} / \mathrm{C}, \mathrm{S} / \mathrm{C}$ and $\mathrm{Cl} / \mathrm{C}$ ratios in the ranges of $0.3-3,0-3,0-1.3,0-0.8$ and $0-0.8$ (Kind and Fiehn, 2007; Lin et al., 2012a; Rincón et al., 2012; Wang et al., 2018; Zielinski et al., 2018), respectively. For chemical formula $\mathrm{C}_{\mathrm{c}} \mathrm{H}_{\mathrm{h}} \mathrm{O}_{\mathrm{o}} \mathrm{N}_{\mathrm{n}} \mathrm{S}_{\mathrm{s}} \mathrm{Cl}_{\mathrm{x}}$, the double bond equivalent (DBE) was calculated by the equation $\mathrm{DBE}=(2 \mathrm{c}+2-\mathrm{h}-\mathrm{x}+\mathrm{n}) / 2$. The aromaticity equivalent $\left(X_{\mathrm{C}}\right)$ as a modified index for aromatic compounds was obtained using the equation: $X_{\mathrm{C}}=[3(\mathrm{DBE}$ $-(p \times o+q \times s))-2] /[\mathrm{DBE}-(p \times o+q \times s)]$, where $p$ and $q$, respectively, refer to the fraction of oxygen and sulfur atoms involved in the $\pi$-bond structure of a compound. As such the values of $p$ and $q$ vary between compound categories (Yassine et al., 2014). For example, carboxylic acids and esters are characterized using $p=q=0.5$, while $p=q=1$ and $p=q=0$ are used for carbonyl and hydroxyl, respectively. Since it is impossible to identify the structures of the hundreds of formulas observed in this study, we cannot know the exact values of $p$ and $q$ in an individual compound. Therefore, in this study, $p=q=0.5$ was applied for compounds detected in ESI- as carboxylic compounds are preferably ionized in negative mode. However, because of the high complexity of the mass spectra in ESI+, $p=q=1$ was used in ESI+ to avoid an overestimation of the amount of aromatics. Moreover, for DBE $\leq(p \times o+q \times s)$ or $X_{\mathrm{C}} \leq 0, X_{\mathrm{C}}$ was defined as zero. Furthermore, in ESI-, for odd numbers of oxygen or sulfur atoms in molecular formulas, the value of $(p \times o+q \times s)$ was rounded down to the lower integer. $X_{\mathrm{C}} \geq 2.50$ and $X_{\mathrm{C}} \geq 2.71$ have been suggested as unambiguous minimum criteria for the presence of monoaromatics and polyaromatics, respectively (Yassine et al., 2014).

Comparing the peak abundance has been performed in recent UHRMS studies (Wang et al., 2017; Fleming et al., 2018; Song et al., 2018; Ning et al., 2019) to illustrate the relative importance of specific types of compounds. However, it should be noted that different organic compounds have different signal responses in the mass spectrometer due to the differences in ionization and transmission efficiencies (Schmidt et al., 2006; Leito et al., 2008; Perry et al., 2008; Kruve et al., 2014). Therefore, uncertainties may exist when comparing the peak areas among compounds. In this work, we assume that all organic compounds have the same peak abundance response in the mass spectrometer. The peak abundance-weighted average molecular mass $(\mathrm{MM})$, elemental ratios, DBE and $X_{C}$ for the formula $\mathrm{C}_{\mathrm{c}} \mathrm{H}_{\mathrm{h}} \mathrm{O}_{\mathrm{o}} \mathrm{N}_{\mathrm{n}} \mathrm{S}_{\mathrm{S}} \mathrm{Cl}_{\mathrm{x}}$ were calculated using following equations.

$$
\begin{aligned}
& \mathrm{MM}_{\mathrm{avg}}=\sum\left(\mathrm{MM}_{i} \times A_{i}\right) / \sum A_{i} \\
& \mathrm{O} / \mathrm{C}_{\mathrm{avg}}=\sum\left(\mathrm{O} / \mathrm{C}_{i} \times A_{i}\right) / \sum A_{i} \\
& \mathrm{H} / \mathrm{C}_{\mathrm{avg}}=\sum\left(\mathrm{H} / \mathrm{C}_{i} \times A_{i}\right) / \sum A \\
& \mathrm{DBE}_{\mathrm{avg}}=\sum\left(\mathrm{DBE}_{i} \times A_{i}\right) / \sum A_{i} \\
& X_{\mathrm{C}_{\mathrm{avg}}}=\sum\left(X_{\mathrm{C}_{i}} \times A_{i}\right) / \sum A_{i}
\end{aligned}
$$

Here $A_{i}$ is the peak abundance for each individual compound $i$.

\section{Results and discussion}

\subsection{General characteristics}

The main purpose of this study was to tentatively identify and compare the chemical composition of organic compounds in the $\mathrm{PM}_{2.5}$ samples collected in the three Chinese cities Changchun, Shanghai and Guangzhou during pollution episodes. To reduce the uncertainty caused by the variability between the samples collected at each location, only organic compounds measured in all three samples of each city are used for intercity comparison. The number of organic compounds and molecular formulas detected in each city, the peak abundance-weighted average values (including the standard deviations of peak abundance of the three sam- 
ples from each city) of molecular mass $\left(\mathrm{MM}_{\mathrm{avg}}\right)$, elemental ratios, DBE, $X_{\mathrm{C}}$, and the isomer number fraction (meaning the percentage of formula numbers that have isomers among all assigned formulas) for each subgroup are listed in Table 1 . It should be noted that in this study we focus solely on organic compounds with elevated signal abundances and thus presumably rather high concentrations. In contrast to our previous study (Wang et al., 2018), compounds with low concentrations were excluded by increasing the reconstitution volume from 500 to $1000 \mu \mathrm{L}$, reducing the sample injection volume from 20 to $10 \mu \mathrm{L}$ and increasing the sample-to-blank ratio from 3 to 10 during data processing.

Overall, 416-769 (assigned to 272-415 molecular formulas) and 687-2943 (assigned to 383-679 molecular formulas) organic compounds in different city samples were determined in ESI- and ESI+, respectively. The largest number of organic compounds was observed in Changchun samples in both ESI- and ESI+, indicating that OA collected during the winter season in northeast China was more complex compared to urban OA in east and southeast China. This increased number of compounds can possibly be explained by the large residential coal combustion emissions in winter in north China (Huang et al., 2014; Song et al., 2018; An et al., 2019), which is consistent with the observation of higher average concentration $\left(46 \pm 20 \mu \mathrm{g} \mathrm{m}^{-3}\right)$ of organic carbon in Changchun than in Shanghai $\left(24 \pm 8 \mu^{-3} \mathrm{~g}^{-3}\right)$ and Guangzhou $\left(25 \pm 2 \mu \mathrm{g} \mathrm{m}^{-3}\right)$ as shown in Table S2. In addition, ambient temperatures were lowest during the sampling period in Changchun (i.e., -14 to $-9^{\circ}$, Table S1), which likely led to a decreased boundary layer height and therefore enhanced accumulation of pollutants and enhanced formation of secondary organic aerosol through for example gas-to-particle partitioning.

As shown in Table 1, the abundance-weighted average values of $\mathrm{MM}_{\mathrm{avg}}$ and $\mathrm{O} / \mathrm{C}$ ratio of the total assigned formulas for Changchun samples detected in negative mode (Changchun-) are 169 and 0.58 , respectively, which are lower than those for Shanghai- $\left(\mathrm{MM}_{\mathrm{avg}}=176\right.$ and $\left.\mathrm{O} / \mathrm{C}=0.69\right)$ and for Guangzhou- $\left(\mathrm{MM}_{\mathrm{avg}}=183\right.$ and $\left.\mathrm{O} / \mathrm{C}=0.74\right)$. On the contrary, the aromaticity equivalent $X_{\mathrm{C}}$ for organics detected in Changchun-, $X_{\mathrm{C}}$ (Changchun-) $=2.13$, is higher than that for Shanghai-, $X_{\mathrm{C}}$ (Shanghai-) $=1.92$, and Guangzhou-, $X_{\mathrm{C}}$ $($ Guangzhou- $)=1.65$. Furthermore, the relative peak abundance fraction of compounds with $\mathrm{O} / \mathrm{C} \geq 0.6$, which are considered to be highly oxidized compounds (Tu et al., 2016), is $31 \%$ in Changchun-, and higher in Shanghai- (46\%) and Guangzhou- $(51 \%)$. These observations indicate that urban OA in northeast China features a lower degree of oxidation and a higher degree of aromaticity compared to urban OA in east and southeast China. The different chemical composition of the samples is probably caused by the rather low ambient temperatures and decreased photochemical processing of organic compounds in northeast China (indicated by the lower solar radiation in northeast China; see Table S1), slowing down oxidation processes and leading to a

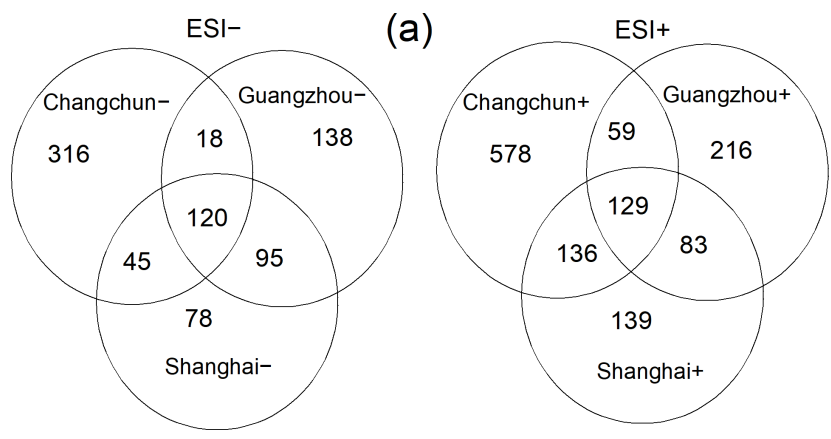

(b)

Common formulas in ESI-

Common formulas in ESI+

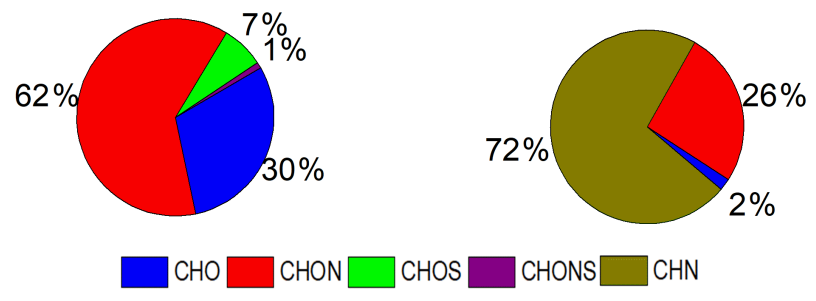

Figure 2. (a) Venn diagrams showing the number distribution of all molecular formulas detected in ESI- and ESI+ for all sample locations. The overlapping molecular formulas refer to the compounds detected in each city with the same molecular formulas and with the same retention times (retention time difference $\leq 0.1 \mathrm{~min}$ ). (b) Peak abundance contribution of each elemental formula category to the total common formulas.

larger number of PAHs, which are mainly emitted from coal burning (Huang et al., 2014; Song et al., 2018) or by different biogenic/anthropogenic precursors. Nitrate is mainly formed by photochemical oxidation, and the average concentration of nitrate (see Table S2) was lower in particle samples from Changchun $\left(15.5 \pm 8.5 \mu \mathrm{g} \mathrm{m}^{-3}\right)$ compared to Shanghai $\left(28.2 \pm 9.4 \mu \mathrm{g} \mathrm{m}^{-3}\right)$ and Guangzhou $\left(24.6 \pm 0.9 \mu \mathrm{g} \mathrm{m}^{-3}\right)$, again indicating less photochemical processing in northeast China. In addition, long-range transport of air masses (see the $48 \mathrm{~h}$ back trajectories in Fig. S1) may have a certain effect on the chemical properties of aerosol samples collected in the three cities.

Figure 1 shows the reconstructed mass spectra of organic compounds detected in ESI- and ESI+. A major fraction of organic species detected in ESI- are attributed to CHO- and CHON-, accounting for $30 \%-42 \%$ and $39 \%-55 \%$ in terms of peak abundance, respectively, and comprising 39\%-45\% and $23 \%-33 \%$ in terms of peak numbers, respectively. This is consistent with previous studies on Chinese urban OA by Wang et al. (2017, 2018) and Brüggemann et al. (2019). Comparing the organic compounds detected in ESI- for the three cities, 120 formulas were observed in all cities as common formulas (which refer to the compounds detected in all cities with the same molecular formulas and with the same retention times; retention time difference $\leq 0.1 \mathrm{~min}$ ) (Fig. 2a), accounting for $29 \%-44 \%$ and $57 \%-71 \%$ of all 
Table 1. Number of organic compounds and molecular formulas in each subgroup and the peak abundance-weighted average values of molecular mass $\left(\mathrm{MM}_{\mathrm{avg}}\right)$, elemental ratios, double bond equivalent (DBE), aromaticity equivalent $\left(X_{\mathrm{C}}\right)$ and isomer number fraction (meaning the percentage of formula numbers that have isomers among all assigned formulas) for detected organic compounds in ESI- and ESI+ in the three Chinese cities.

\begin{tabular}{|c|c|c|c|c|c|c|c|c|c|}
\hline $\begin{array}{l}\text { Sample } \\
\text { ID }\end{array}$ & Subgroup & $\begin{array}{r}\text { Number } \\
\text { of } \\
\text { compounds }^{\mathrm{a}}\end{array}$ & $\begin{array}{r}\text { Relative } \\
\text { abundance } \\
(\%)\end{array}$ & $\mathrm{MM}_{\mathrm{avg}}$ & $\mathrm{H} / \mathrm{C}$ & $\mathrm{O} / \mathrm{C}^{\mathrm{b}}$ & DBE & $X_{\mathrm{C}}$ & $\begin{array}{r}\text { Isomer } \\
\text { number } \\
\text { fraction } \\
(\%)\end{array}$ \\
\hline \multirow[t]{5}{*}{ Changchun- } & Total & $769(415)$ & $100 \pm 0$ & $169 \pm 3$ & $1.03 \pm 0.01$ & $0.58 \pm 0.01$ & $5.02 \pm 0.01$ & $2.13 \pm 0.03$ & 34 \\
\hline & CHO- & $346(136)$ & $30 \pm 1$ & $162 \pm 2$ & $0.96 \pm 0.01$ & $0.41 \pm 0.02$ & $5.65 \pm 0.08$ & $2.28 \pm 0.03$ & 52 \\
\hline & CHON- & $180(96)$ & $55 \pm 4$ & $163 \pm 2$ & $0.94 \pm 0.01$ & $0.51 \pm 0.00$ & $5.24 \pm 0.01$ & $2.44 \pm 0.01$ & 36 \\
\hline & CHOS- & $155(105)$ & $10 \pm 2$ & $198 \pm 3$ & $1.56 \pm 0.11$ & $\begin{array}{r}1.17 \pm 0.13 \\
(0.52 \pm 0.07)\end{array}$ & $2.55 \pm 0.40$ & $0.50 \pm 0.12$ & 28 \\
\hline & CHONS- & $88(78)$ & $5 \pm 1$ & $214 \pm 8$ & $1.35 \pm 0.02$ & $\begin{array}{r}1.07 \pm 0.11 \\
(-1.4 \pm 0.06)\end{array}$ & $3.75 \pm 0.18$ & $1.06 \pm 0.14$ & 8 \\
\hline \multirow{5}{*}{ Shanghai- } & Total & $416(272)$ & $100 \pm 0$ & $176 \pm 2$ & $1.05 \pm 0.04$ & $0.69 \pm 0.06$ & $4.99 \pm 0.15$ & $1.92 \pm 0.09$ & 31 \\
\hline & $\mathrm{CHO}-$ & $164(90)$ & $40 \pm 3$ & $171 \pm 2$ & $0.97 \pm 0.05$ & $0.59 \pm 0.03$ & $5.37 \pm 0.31$ & $1.94 \pm 0.13$ & 41 \\
\hline & CHON- & $135(89)$ & $44 \pm 4$ & $169 \pm 2$ & $0.86 \pm 0.01$ & $0.56 \pm 0.01$ & $5.67 \pm 0.03$ & $2.47 \pm 0.01$ & 37 \\
\hline & CHOS- & $75(62)$ & $12 \pm 5$ & $190 \pm 4$ & $1.85 \pm 0.04$ & $\begin{array}{r}1.41 \pm 0.19 \\
(0.61 \pm 0.11)\end{array}$ & $1.79 \pm 0.15$ & $0.34 \pm 0.02$ & 15 \\
\hline & CHONS- & $42(31)$ & $4 \pm 2$ & $266 \pm 19$ & $1.56 \pm 0.03$ & $\begin{array}{r}1.00 \pm 0.13 \\
(0.11 \pm 0.05)\end{array}$ & $3.30 \pm 0.26$ & $0.44 \pm 0.10$ & 13 \\
\hline \multirow[t]{5}{*}{ Guangzhou- } & Total & $488(304)$ & $100 \pm 0$ & $183 \pm 2$ & $1.14 \pm 0.01$ & $0.74 \pm 0.02$ & $4.55 \pm 0.06$ & $1.65 \pm 0.02$ & 34 \\
\hline & CHO- & $196(110)$ & $42 \pm 4$ & $172 \pm 1$ & $1.10 \pm 0.01$ & $0.65 \pm 0.00$ & $4.68 \pm 0.08$ & $1.57 \pm 0.03$ & 44 \\
\hline & CHON- & 161(98) & $39 \pm 4$ & $173 \pm 3$ & $0.89 \pm 0.01$ & $0.58 \pm 0.01$ & $5.56 \pm 0.06$ & $2.41 \pm 0.01$ & 35 \\
\hline & CHOS- & $86(67)$ & $14 \pm 2$ & $201 \pm 1$ & $1.85 \pm 0.02$ & $\begin{array}{r}1.48 \pm 0.05 \\
(0.71 \pm 0.03)\end{array}$ & $1.71 \pm 0.09$ & $0.21 \pm 0.04$ & 21 \\
\hline & CHONS- & $45(29)$ & $5 \pm 1$ & $293 \pm 5$ & $1.56 \pm 0.04$ & $\begin{array}{r}0.82 \pm 0.03 \\
(0.06 \pm 0.15)\end{array}$ & $3.45 \pm 0.06$ & $0.43 \pm 0.10$ & 28 \\
\hline \multirow[t]{5}{*}{ Changchun+ } & Total & 2943(679) & $100 \pm 0$ & $160 \pm 1$ & $1.21 \pm 0.03$ & $0.13 \pm 0.02$ & $5.58 \pm 0.19$ & $2.36 \pm 0.06$ & 56 \\
\hline & $\mathrm{CHO}+$ & $609(162)$ & $13 \pm 2$ & $174 \pm 3$ & $0.94 \pm 0.01$ & $0.28 \pm 0.02$ & $6.55 \pm 0.27$ & $2.22 \pm 0.06$ & 50 \\
\hline & $\mathrm{CHN}+$ & $696(126)$ & $40 \pm 5$ & $154 \pm 2$ & $1.22 \pm 0.03$ & $0.00 \pm 0$ & $5.84 \pm 0.19$ & $2.60 \pm 0.02$ & 77 \\
\hline & $\mathrm{CHON}+$ & $1594(352)$ & $46.5 \pm 3$ & $161 \pm 1$ & $1.27 \pm 0.03$ & $0.19 \pm 0.01$ & $5.11 \pm 0.14$ & $2.22 \pm 0.04$ & 55 \\
\hline & CHONS+ & $44(39)$ & $0.5 \pm 0.3$ & $196 \pm 20$ & $1.91 \pm 0.31$ & $0.70 \pm 0.15$ & $2.64 \pm 0.64$ & $0.09 \pm 0.01$ & 13 \\
\hline \multirow[t]{5}{*}{ Shanghai+ } & Total & $704(383)$ & $100 \pm 0$ & $162 \pm 1$ & $1.37 \pm 0.03$ & $0.09 \pm 0.04$ & $4.91 \pm 0.10$ & $2.32 \pm 0.14$ & 32 \\
\hline & $\mathrm{CHO}+$ & $87(67)$ & $4 \pm 1$ & $184 \pm 2$ & $1.13 \pm 0.12$ & $0.43 \pm 0.02$ & $5.46 \pm 0.67$ & $1.46 \pm 0.24$ & 19 \\
\hline & $\mathrm{CHN}+$ & $253(84)$ & $71 \pm 15$ & $159 \pm 2$ & $1.38 \pm 0.04$ & $0.00 \pm 0$ & $5.08 \pm 0.17$ & $2.55 \pm 0.03$ & 54 \\
\hline & $\mathrm{CHON}+$ & $350(218)$ & $24.7 \pm 13$ & $167 \pm 2$ & $1.40 \pm 0.01$ & $0.27 \pm 0.02$ & $4.34 \pm 0.10$ & $1.81 \pm 0.05$ & 30 \\
\hline & CHONS+ & $14(14)$ & $0.3 \pm 0.3$ & $241 \pm 15$ & $1.17 \pm 0.18$ & $0.61 \pm 0.12$ & $5.32 \pm 1.11$ & $0.91 \pm 0.42$ & 0 \\
\hline \multirow[t]{5}{*}{ Guangzhou+ } & Total & $687(412)$ & $100 \pm 0$ & $161 \pm 1$ & $1.41 \pm 0.02$ & $0.17 \pm 0.05$ & $4.58 \pm 0.14$ & $2.07 \pm 0.15$ & 30 \\
\hline & $\mathrm{CHO}+$ & $125(87)$ & $8 \pm 2$ & $185 \pm 1$ & $1.12 \pm 0.02$ & $0.42 \pm 0.00$ & $5.19 \pm 0.09$ & $1.20 \pm 0.02$ & 26 \\
\hline & $\mathrm{CHN}+$ & $205(78)$ & $62 \pm 9$ & $156 \pm 1$ & $1.42 \pm 0.02$ & $0.00 \pm 0$ & $4.80 \pm 0.11$ & $2.47 \pm 0.04$ & 54 \\
\hline & $\mathrm{CHON}_{+}$ & $336(227)$ & $29 \pm 6$ & $165 \pm 1$ & $1.47 \pm 0.04$ & $0.45 \pm 0.04$ & $4.00 \pm 0.18$ & $1.51 \pm 0.10$ & 26 \\
\hline & CHONS+ & $21(20)$ & $1 \pm 0.4$ & $209 \pm 3$ & $1.84 \pm 0.05$ & $0.71 \pm 0.01$ & $3.05 \pm 0.11$ & $0.31 \pm 0.04$ & 5 \\
\hline
\end{tabular}

The standard uncertainty is the standard deviations of peak abundance of the three samples from each city. ${ }^{\text {a }}$ The values in brackets indicate the number of unique molecular formulas. ${ }^{b}$ The values in brackets indicate the (O-3S) / C and (O-3S-2N) / C ratios for CHOS and CHONS compounds, respectively, detected in ESI- mode. 
assigned formulas in terms of formula numbers and peak abundance, respectively. Despite the abovementioned differences in chemical composition for OA from Changchun compared to OA from Shanghai and Guangzhou, these results demonstrate that still a large number of common organic compounds exist in Chinese urban OAs collected in different cities, in particular for organics with higher signal abundances. Furthermore, as shown by the pie chart in Fig. $2 \mathrm{~b}$, these common formulas are dominated by $\mathrm{CHON}$ and CHO-, accounting for $62 \%$ and $30 \%$ of the total common formulas in terms of peak abundance, respectively.

As is commonly known, ESI exhibits different ionization mechanisms in negative and positive ionization modes. While ESI- is especially sensitive to deprotonatable compounds (e.g., organic acids), ESI+ is more sensitive to protonatable compounds (e.g., organic amines) (Ho et al., 2003). Due to the different ionization mechanisms, clear differences were observed in the mass spectra (Fig. 1) and chemical characteristics (Table 1) from ESI- and ESI+ measurements. For example, $\mathrm{CHO}$ compounds were preferentially detected in ESI-, accounting for a relatively larger fraction of $30 \%-$ $42 \%$ of all detected compounds in terms of peak abundance, compared to merely $4 \%-13 \%$ for such $\mathrm{CHO}$ compounds in ESI+. In contrast, CHN compounds were only observed in ESI+, yielding a rather large peak abundance fraction of $40 \%-71 \%$. In particular, as can be seen in Fig. 1, several peaks of CHN+ compounds in Shanghai+ and Guangzhou+ have much higher abundance compared to other organic species, probably due to their high concentrations and/or high ionization efficiencies in the positive mode. This observation indicates that most $\mathrm{CHO}$ compounds with high concentrations are probably organic acids, whereas the majority of CHN compounds likely belong to the group of organic amines, which is in good agreement with previous studies (Lin et al., 2012a; Wang et al., 2017, 2018). Organic compounds in ESI+ are dominated by $\mathrm{CHN}+$ and $\mathrm{CHON}+$ compounds in terms of both peak numbers and peak abundance, and these compounds are characterized by rather high $\mathrm{H} / \mathrm{C}$ ratio and low $\mathrm{O} / \mathrm{C}$ ratios (Table 1), indicating a low degree of oxidation. The Venn diagram presented for ESI+ measurements in Fig. 2a shows that out of a total of 383-679 formulas, 129 formulas were found in samples from all three cities. Such common formulas, thus, account for $19 \%-34 \%$ and $30 \%-75 \%$ of all assigned formulas in terms of formula numbers and peak abundance, respectively. Among these common formulas, $\mathrm{CHN}+$ and $\mathrm{CHON}+$ exhibit the highest abundance fractions of $72 \%$ and $26 \%$, respectively (Fig. 2b).

In the following, we will compare and discuss the chemical properties in detail for the three cities, including degrees of oxidation, unsaturation and aromaticity of each organic compound class (i.e., $\mathrm{CHO}, \mathrm{CHON}, \mathrm{CHN}, \mathrm{CHOS}$ and CHONS). It should be noted that the chlorine-containing compounds were not discussed in this study due to the very low MS signal abundance. In addition, since peak abundances for the formula can vary by orders of magnitude, the
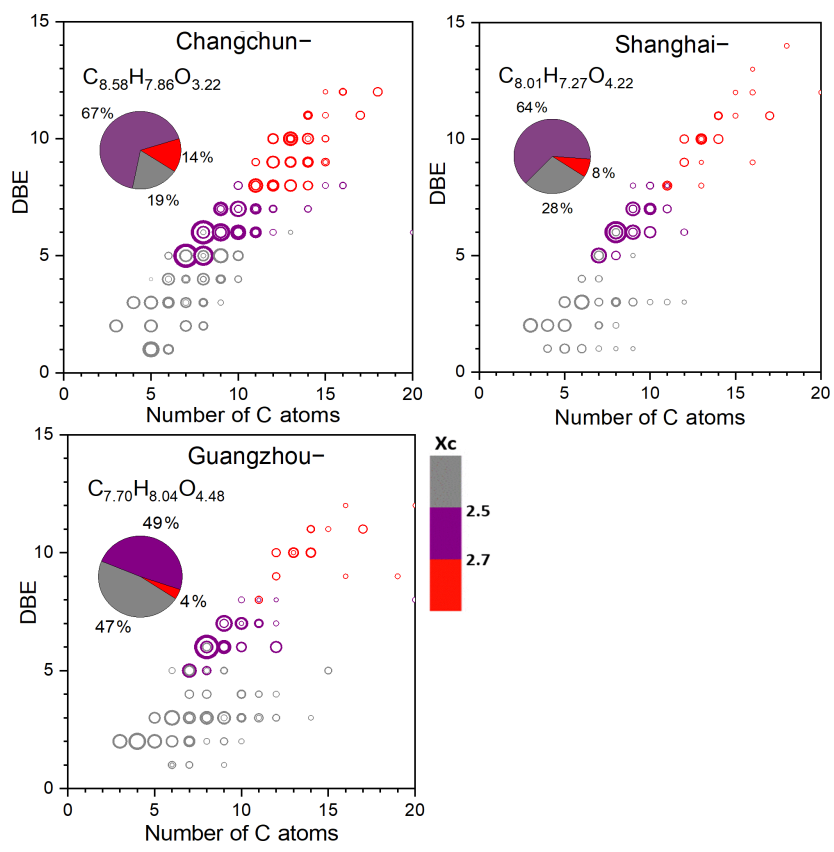

Figure 3. Double bond equivalent (DBE) versus carbon number for all CHO- compounds for all sample locations. The molecular formula represents the abundance-weighted average $\mathrm{CHO}$ - formula, and the area of the circles is proportional to the fourth root of the peak abundance of an individual compound (a diagram with circle areas related to the absolute peak abundances is presented in Fig. S2). The color bar denotes the aromaticity equivalent (gray with $X_{\mathrm{C}}<2.50$, purple with $2.50 \leq X_{\mathrm{C}}<2.70$ and red with $X_{\mathrm{C}} \geq$ 2.70). The pie charts show the percentage of each $X_{\mathrm{C}}$ category (i.e., gray color-coded compounds, purple color-coded compounds and red color-coded compounds) in each sample in terms of peak abundance.

area of the circles presented in Figs. 3 and 5-7 is proportional to the fourth root of the peak abundance of each formula to reduce the size difference of the circles. For a more detailed comparison, figures with the circle size related to the absolute peak abundances are presented in the Supplement.

\subsection{CHO compounds}

CHO compounds have been widely observed in urban OA, accounting for a substantial fraction $(8 \%-67 \%)$ of OA (Rincón et al., 2012; Tao et al., 2014; Wang et al., 2017, 2018). Previous studies have shown that a large fraction of $\mathrm{CHO}$ compounds in urban OA are composed of organic acids, containing deprotonatable carboxyl functional groups, which are detected preferentially in negative ionization mode when using ESI-MS. As shown in Table 1, a total of 346, 164 and 196 CHO- compounds were detected in ESI- in the OA samples collected in Changchun, Shanghai and Guangzhou, accounting for $30 \%, 40 \%$ and $42 \%$ of the overall peak abundance in each sample, respectively. Out of all assigned formulas, 47 common $\mathrm{CHO}$ - formulas were observed for all 
cites, accounting for $35 \%-52 \%$ and $42 \%-68 \%$ of all identified CHO- formulas in terms of formula numbers and peak abundance, respectively.

Despite this similarity, OA samples from Changchun- (i.e., in negative ionization mode) exhibit certain differences compared to samples from Shanghai- and Guangzhou-. The average $\mathrm{H} / \mathrm{C}$ values for $\mathrm{CHO}$ - compounds are in a similar range for the three locations (i.e., 0.96-1.10); however, the average $\mathrm{O} / \mathrm{C}$ values for $\mathrm{O} / \mathrm{C}$ (Shanghai-) $=0.59$ and $\mathrm{O} / \mathrm{C}$ $($ Guangzhou- $)=0.65$ are rather high compared to the average $\mathrm{O} / \mathrm{C}$ ratio for Changchun-, $\mathrm{O} / \mathrm{C}$ (Changchun-) $=0.41$. Furthermore, the relative peak abundance fraction of CHO- compounds with $\mathrm{O} / \mathrm{C} \geq 0.6$, which are considered to be highly oxidized compounds (Tu et al., 2016), is $14 \%$ in Changchun and somewhat higher in Shanghai- (34\%) and Guangzhou$(45 \%)$. Altogether, these results indicate that CHO- compounds in urban OA from east and southeast China experienced more intense oxidation and aging processes and/or were affected to a larger degree by biogenic sources.

Similarly, as shown in Fig. 3, the abundance-weighted average molecular formulas for $\mathrm{CHO}$ - compounds in Changchun-, Shanghai- and Guangzhou- $\operatorname{are} \mathrm{C}_{8.58} \mathrm{H}_{7.86} \mathrm{O}_{3.22}$ $\left(\mathrm{MM}_{\text {avg }} \quad(\right.$ Changchun- $\left.)=162\right), \mathrm{C}_{8.01} \mathrm{H}_{7.27} \mathrm{O}_{4.22} \quad\left(\mathrm{MM}_{\mathrm{avg}}\right.$ $($ Shanghai- $)=171) \quad$ and $\quad \mathrm{C}_{7.70} \mathrm{H}_{8.04} \mathrm{O}_{4.48} \quad\left(\mathrm{MM}_{\mathrm{avg}}\right.$ $($ Guangzhou- $)=172)$, respectively. Again, these average formulas show that CHO- in Shanghai- and Guangzhouexperienced more intense oxidation processes and/or were affected to a larger degree by biogenic precursors, indicated by the larger abundance-weighted $\mathrm{MM}_{\mathrm{avg}}$ with a higher degree of oxygenation. In contrast, $\mathrm{CHO}$ - compounds from $\mathrm{OA}$ samples in Changchun- exhibit a lower abundance-weighted $\mathrm{MM}_{\text {avg }}$ with a decreased oxygen content.

Besides oxygenation, the aromaticity of the detected CHO- compounds exhibits remarkable differences in these three cities. In all cities, the CHO- compounds with high peak abundance were mainly assigned to monoaromatics with $2.5 \leq X_{\mathrm{C}}<2.7$ (purple circles in Fig. 3) in the region of 7-12 carbon atoms per compound and DBE values of 5-7. The relative peak abundance fraction of monoaromatics in total CHO- compounds is $67 \%$ in Changchun, which is higher compared to $64 \%$ in Shanghai and $49 \%$ in Guangzhou. In addition, $14 \%$ of $\mathrm{CHO}$ - compounds in Changchun were identified as polyaromatic compounds with $X_{\mathrm{C}} \geq 2.7$ (red circles in Fig. 3), which is higher than the $8 \%$ in Shanghai and $4 \%$ in Guangzhou. These observations indicate that CHO- compounds in the three Chinese cities are highly affected by aromatic precursors (e.g., benzene, toluene and naphthalene), in particular for the Changchun aerosol samples.

Besides the monoaromatics and polyaromatics, the rest of the detected CHO- compounds were assigned to aliphatic compounds with an $X_{\mathrm{C}}$ lower than 2.5 (gray circles in Fig. 3). Interestingly, these aliphatic compounds account for about $47 \%$ of all CHO- compounds for Guangzhou- samples in terms of peak abundance, whereas samples from Changchun- and Shanghai- exhibit only rather small fractions of such CHO- compounds, i.e., $19 \%$ and $28 \%$, respectively. Such aliphatic compounds are commonly derived from biogenic precursors (Kourtchev et al., 2016) and vehicle emission (Tao et al., 2014; Wang et al., 2017) and/or generated by intense oxidation processes of aromatic precursors, indicating the different biogenic and anthropogenic emission sources and chemical reaction processes for OAs in the three cities.

In addition, through the analysis of individual formulas, we find that for the Changchun- samples, formulas of $\mathrm{C}_{8} \mathrm{H}_{6} \mathrm{O}_{4}, \mathrm{C}_{7} \mathrm{H}_{6} \mathrm{O}_{2}, \mathrm{C}_{7} \mathrm{H}_{6} \mathrm{O}_{3}, \mathrm{C}_{7} \mathrm{H}_{6} \mathrm{O}_{3}$ and $\mathrm{C}_{8} \mathrm{H}_{8} \mathrm{O}_{3}$ with DBE values of $6,5,5,5$ and 5 dominate the assigned $\mathrm{CHO}$ formulas with respect to peak abundance. According to previous studies, $\mathrm{C}_{8} \mathrm{H}_{6} \mathrm{O}_{4}, \mathrm{C}_{7} \mathrm{H}_{6} \mathrm{O}_{2}$ and $\mathrm{C}_{7} \mathrm{H}_{6} \mathrm{O}_{3}$ are suggested to be phthalic acid, benzoic acid and monohydroxy benzoic acid, respectively, which are derived from naphthalene (Kautzman et al., 2010; Riva et al., 2015; Wang et al., 2017; $\mathrm{He}$ et al., 2018; Huang et al., 2019). $\mathrm{C}_{7} \mathrm{H}_{6} \mathrm{O}_{3}$ is likely 4hydroxy acetophenone, which could be derived from estragole (Pereira et al., 2014), while $\mathrm{C}_{8} \mathrm{H}_{8} \mathrm{O}_{3}$ is suggested to be either 4-methoxybenzoic acid generated from estragole (Pereira et al., 2014) or vanillin emitted from biomass burning ( $\mathrm{Li}$ et al., 2014). For the Shanghai- samples, besides $\mathrm{C}_{8} \mathrm{H}_{6} \mathrm{O}_{4}, \mathrm{C}_{7} \mathrm{H}_{6} \mathrm{O}_{3}$ and $\mathrm{C}_{7} \mathrm{H}_{6} \mathrm{O}_{2}$, formulas of $\mathrm{C}_{6} \mathrm{H}_{8} \mathrm{O}_{7}$ and $\mathrm{C}_{9} \mathrm{H}_{8} \mathrm{O}_{4}$ with DBE values of 3 and 6 were observed with high peak abundances. $\mathrm{C}_{6} \mathrm{H}_{8} \mathrm{O}_{7}$ was identified as citric acid in the pollen sample and mountain particle sample in previous studies (Fu et al., 2008; Wang et al., 2009; Jung and Kawamura, 2011), and $\mathrm{C}_{9} \mathrm{H}_{8} \mathrm{O}_{4}$ is probably homophthalic acid derived from estragole (Pereira et al., 2014). For the Guangzhou- samples, besides the formulas of $\mathrm{C}_{8} \mathrm{H}_{6} \mathrm{O}_{4}$ and $\mathrm{C}_{6} \mathrm{H}_{8} \mathrm{O}_{7}$ discussed above, $\mathrm{C}_{4} \mathrm{H}_{6} \mathrm{O}_{4}$ and $\mathrm{C}_{4} \mathrm{H}_{6} \mathrm{O}_{5}$ with low DBE values of 2 were detected with high abundances and are suggested to be succinic acid and malic acid, respectively (Claeys et al., 2004; Wang et al., 2017).

\subsection{CHON compounds}

A large number of nitrogen-containing organic compounds were detected in these three cities, accounting for $39 \%-55 \%$ and $25 \%-47 \%$ of total peak abundance detected in ESI- and ESI+, respectively. Out of all assigned formulas, 45 common CHON- and 62 common $\mathrm{CHON}+$ formulas were observed in all cities, accounting for $65 \%-82 \%$ and $25 \%-$ $44 \%$ of all CHON compounds detected in ESI- and ESI+ in terms of peak abundance, respectively. This indicates that a large number of CHON compounds in all three Chinese cities show similar properties of chemical composition.

The CHON compounds were further classified into different subgroups according to their $\mathrm{O} / \mathrm{N}$ ratios (Fig. 4 for $\mathrm{CHON}$ - and Fig. S3 for $\mathrm{CHON+}+$ or according to the number of nitrogen atoms in their molecular formulas (see Fig. S4 for CHON- and $\mathrm{S} 5$ for $\mathrm{CHON+}+$. As shown in Fig. 4, the majority ( $84 \%-96 \%$ in terms of peak abundance) of CHON- compounds exhibited $\mathrm{O} / \mathrm{N}$ ratios $\geq 3$, allowing the assignment of 


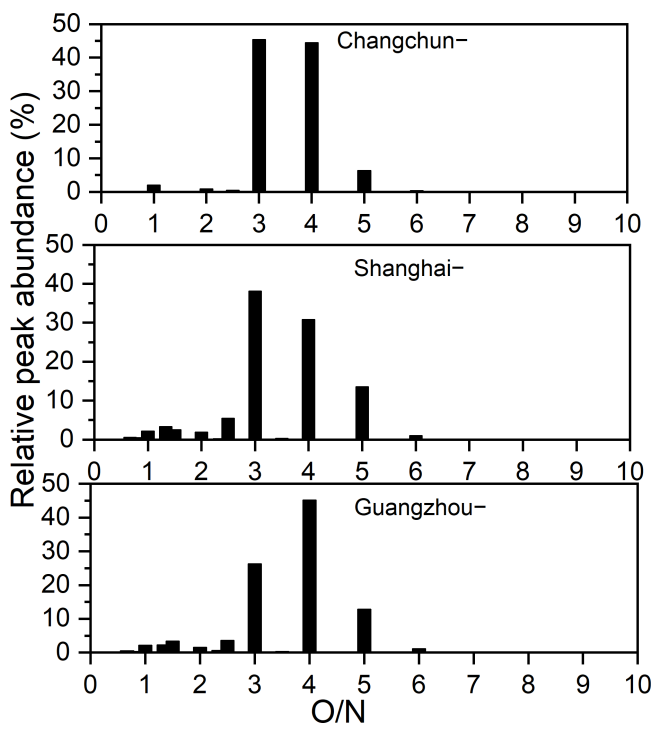

Figure 4. Classification of CHON- compounds into different subgroups according to $\mathrm{O} / \mathrm{N}$ ratios in their formulas. The $y$ axis indicates the relative contribution of each specific $\mathrm{O} / \mathrm{N}$ ratio subgroup to the sum of peak abundances of $\mathrm{CHON}$ - compounds.

one nitro $\left(-\mathrm{NO}_{2}\right)$ or nitrooxy $\left(-\mathrm{ONO}_{2}\right)$ group for these formulas, which are preferentially ionized in ESI- mode (Lin et al., 2012b; Wang et al., 2017, 2018; Song et al., 2018). $\mathrm{CHON}$ - formulas with $\mathrm{O} / \mathrm{N}$ ratios $\geq 4$ suggest the presence of further oxygenated functional groups, such as a hydroxyl group (-OH) or a carbonyl group $(\mathrm{C}=\mathrm{O})$. In terms of peak abundance, $59 \%$ of CHON- compounds observed in Guangzhou- exhibited formulas with $\mathrm{O} / \mathrm{N}$ ratios $\geq 4$, which is higher than $51 \%$ in Changchun- and $45 \%$ in Shanghai-, indicating that $\mathrm{CHON}$ - compounds in southeast China show a higher degree of oxidation compared to those in northeast and east China. Not surprisingly, $\mathrm{CHON}+$ compounds generally exhibit lower $\mathrm{O} / \mathrm{N}$ ratios (Fig. S3), as they probably contain a reduced nitrogen functional group (e.g., amines), which is preferably detected in ESI+. As shown in Fig. S3, $\mathrm{CHON}+$ compounds with an $\mathrm{O} / \mathrm{N}$ ratio of 1 are dominant in Changchun+, whereas CHON+ compounds in Shanghai+ and Guangzhou+ show a broader range of $\mathrm{O} / \mathrm{N}$ ratios from 1 to 3. Moreover, the average $\mathrm{O} / \mathrm{C}$ ratios $(0.27-0.45)$ in Shanghai+ and Guangzhou+ (Table 1) are much greater than those (0.19) in Changchun+. Consistent with the observations for $\mathrm{CHO}$ compounds, these results indicate again that $\mathrm{CHON}+$ compounds in the OA of east and southeast China experienced more intensive photooxidation and/or were affected to a larger degree by biogenic precursors.

Figure 5 shows the DBE versus $\mathrm{C}$ number of $\mathrm{CHON}$ compounds for the three cities. The majority of CHONcompounds lie in the region of 5-15C atoms and 3-10 DBEs. A total of $67 \%$ of CHON- compounds in terms of peak abundance were assigned to mono or polyaromatics in Shanghai-, which is higher than $52 \%$ in Guangzhou-
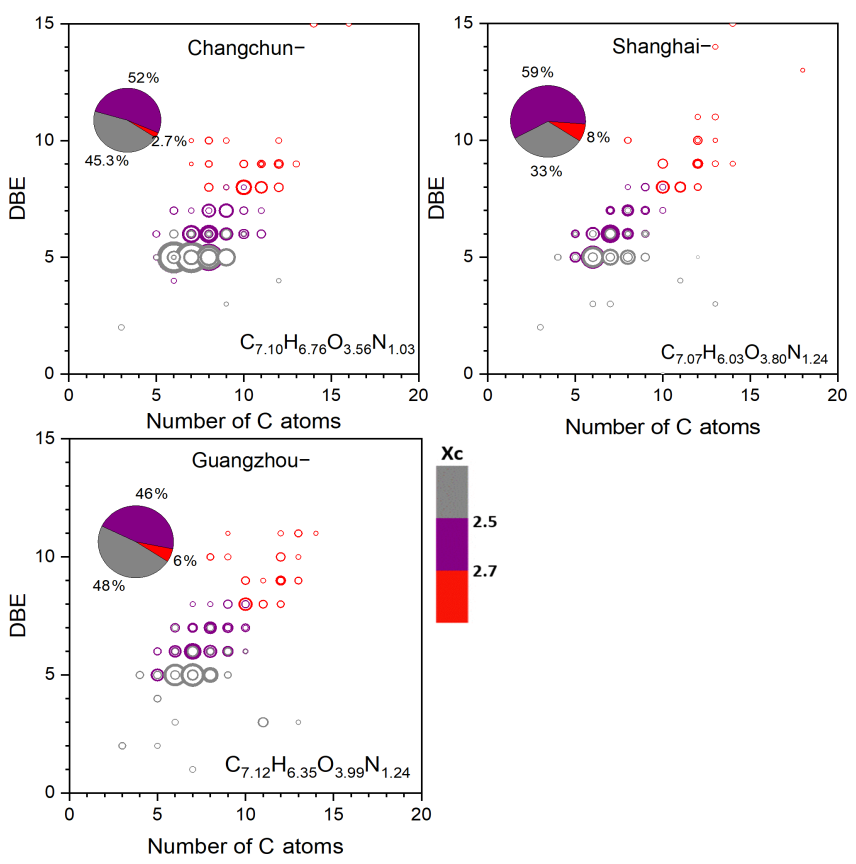

Figure 5. Double bond equivalent (DBE) versus carbon number for all $\mathrm{CHON}$ - compounds for all sample locations. The molecular formula represents the abundance-weighted average $\mathrm{CHON}$ - formula, and the area of circles is proportional to the fourth root of the peak abundance of an individual compound (a diagram with circle areas related to absolute peak abundances is presented in Fig. S6). The color bar denotes the aromaticity equivalent (gray with $X_{\mathrm{C}}<$ 2.50, purple with $2.50 \leq X_{\mathrm{C}}<2.70$ and red with $X_{\mathrm{C}} \geq 2.70$ ). The pie charts show the percentage of each $X_{\mathrm{C}}$ category (i.e., gray colorcoded compounds, purple color-coded compounds and red colorcoded compounds) in each sample in terms of peak abundance.

and $55 \%$ in Changchun-. This indicates that CHON- compounds are dominated by aromatic compounds in all cities, while relatively higher peak abundance-weighted fraction of aromatic CHON- compounds were observed in Shanghai. The peak abundance-weighted average molecular formulas for CHON- compounds in Changchun-, Shanghai- and Guangzhou- are $\mathrm{C}_{7.10} \mathrm{H}_{6.76} \mathrm{O}_{3.56} \mathrm{~N}_{1.03}, \mathrm{C}_{7.07} \mathrm{H}_{6.03} \mathrm{O}_{3.80} \mathrm{~N}_{1.24}$ and $\mathrm{C}_{7.12} \mathrm{H}_{6.36} \mathrm{O}_{3.99} \mathrm{~N}_{1.24}$, respectively, showing that $\mathrm{CHON}$ formulas in Shanghai- and Guangzhou- contain more O and $\mathrm{N}$ atoms on average than those for Changchun-. Formulas of $\mathrm{C}_{6} \mathrm{H}_{5} \mathrm{O}_{3} \mathrm{~N}_{1}, \mathrm{C}_{6} \mathrm{H}_{5} \mathrm{O}_{4} \mathrm{~N}_{1}, \mathrm{C}_{7} \mathrm{H}_{7} \mathrm{O}_{3} \mathrm{~N}_{1}, \mathrm{C}_{7} \mathrm{H}_{7} \mathrm{O}_{4} \mathrm{~N}_{1}$, $\mathrm{C}_{8} \mathrm{H}_{9} \mathrm{O}_{3} \mathrm{~N}_{1}$ and $\mathrm{C}_{8} \mathrm{H}_{9} \mathrm{O}_{4} \mathrm{~N}_{1}$ were detected with the highest abundance in all cities. These molecular formulas are in line with nitrophenol or nitrocatechol analogs, which have been identified in a previous urban OA study (Wang et al., 2017). Furthermore, these nitrooxy-aromatic compounds were shown to enhance light-absorbing properties of OA (Laskin et al., 2015; Lin et al., 2015). In addition, it should be noted that the $X_{\mathrm{C}}$ values for $\mathrm{C}_{6} \mathrm{H}_{5} \mathrm{O}_{4} \mathrm{~N}_{1}, \mathrm{C}_{7} \mathrm{H}_{7} \mathrm{O}_{4} \mathrm{~N}_{1}$ and $\mathrm{C}_{7} \mathrm{H}_{7} \mathrm{O}_{4} \mathrm{~N}_{1}$ were calculated to be lower than 2.5, suggesting that the fraction of aromatics in $\mathrm{CHON}$ - compounds was un- 
derestimated. This is because that for nitrocatechol analogs with formulas of $\mathrm{C}_{6} \mathrm{H}_{5} \mathrm{O}_{4} \mathrm{~N}_{1}, \mathrm{C}_{7} \mathrm{H}_{7} \mathrm{O}_{4} \mathrm{~N}_{1}$ and $\mathrm{C}_{8} \mathrm{H}_{9} \mathrm{O}_{4} \mathrm{~N}_{1}$, only one oxygen atom is involved in the $\pi$-bond structure corresponding to the $p$ value of 0.25 in the $X_{\mathrm{C}}$ calculation equation, which is lower than the $p$ value of 0.5 applied for the $X_{\mathrm{C}}$ calculation in this study. The diagram of DBE versus $\mathrm{C}$ number for $\mathrm{CHON}+$ compounds observed in the three locations (presented in Fig. S7 in the Supplement) shows that more aromatic $\mathrm{CHON}+$ compounds with relatively lower degree of oxidation were assigned in Changchun+ samples compared to Shanghai+ and Guangzhou+ samples.

\subsection{CHN+ compounds}

A total of $696 \mathrm{CHN}+$ compounds were detected in Changchun+ samples in ESI+, which is higher than in Shanghai+ (253) and Guangzhou (205). These CHN+ compounds are likely assignable to amines according to previous studies (Rincón et al., 2012; Wang et al., 2017, 2018). The number of $\mathrm{CHN}+$ compounds accounts for $24 \%, 36 \%$ and $30 \%$ of the total organic compounds in Changchun+, Shanghai+ and Guangzhou+, respectively, whereas the peak abundance of these compounds accounts for $40 \%, 71 \%$ and $62 \%$, respectively. The majority ( $>97 \%$ in terms of peak abundance) of $\mathrm{CHN}+$ compounds have one or two nitrogen atoms in their molecular formulas (see Fig. S9). Comparing the $\mathrm{CHN}+$ compounds for the three cities, 51 common $\mathrm{CHN}+$ formulas were observed in all cities, which contribute to as much as $43 \%-89 \%$ of the total abundance of $\mathrm{CHN}+$ formulas. This large percentage indicates that $\mathrm{CHN}+$ compounds with presumably high concentrations in Changchun+, Shanghai+ and Guangzhou+ exhibit similar chemical composition. However, again OA samples from Changchun show some distinct differences to samples from Guangzhou and Shanghai.

A van Krevelen diagram of $\mathrm{CHN}+$ compounds detected in the three samples is shown in Fig. 6, illustrating $\mathrm{H} / \mathrm{C}$ ratios as a function of $\mathrm{N} / \mathrm{C}$ ratio. In this plot, major parts of the $\mathrm{CHN}+$ compounds are found in a region that is constrained by $\mathrm{H} / \mathrm{C}$ ratios between 0.5 and 2 and $\mathrm{N} / \mathrm{C}$ ratios lower than 0.5 . Moreover, the pie charts show that the majority $(83 \%-$ $87 \%$ in terms of peak abundance and $72 \%-90 \%$ in terms of peak numbers) of these $\mathrm{CHN}+$ compounds can be assigned to mono- and polyaromatics with $X_{\mathrm{C}} \geq 2.5$. In addition, as shown in Table 1 , the average DBE and $X_{\mathrm{C}}$ values of $\mathrm{CHN}+$ compounds are the highest among all organic species. These observations imply that $\mathrm{CHN}+$ compounds exhibit the highest degree of aromaticity of all organics in the Chinese urban OA samples, which is consistent with previous studies (Lin et al., 2012b; Rincón et al., 2012; Wang et al., 2018). Polyaromatic compounds with $X_{\mathrm{C}} \geq 2.7$ are displayed in the lower left corner of the van Krevelen diagram, accounting for $41 \%$ in terms of peak abundance ( $48 \%$ in terms of peak numbers) of $\mathrm{CHN}+$ compounds detected in Changchun+, but merely for $9 \%-10 \%$ in terms of peak abundance $(27 \%-31 \%$ in terms of peak numbers) in Shanghait and Guangzhou+.
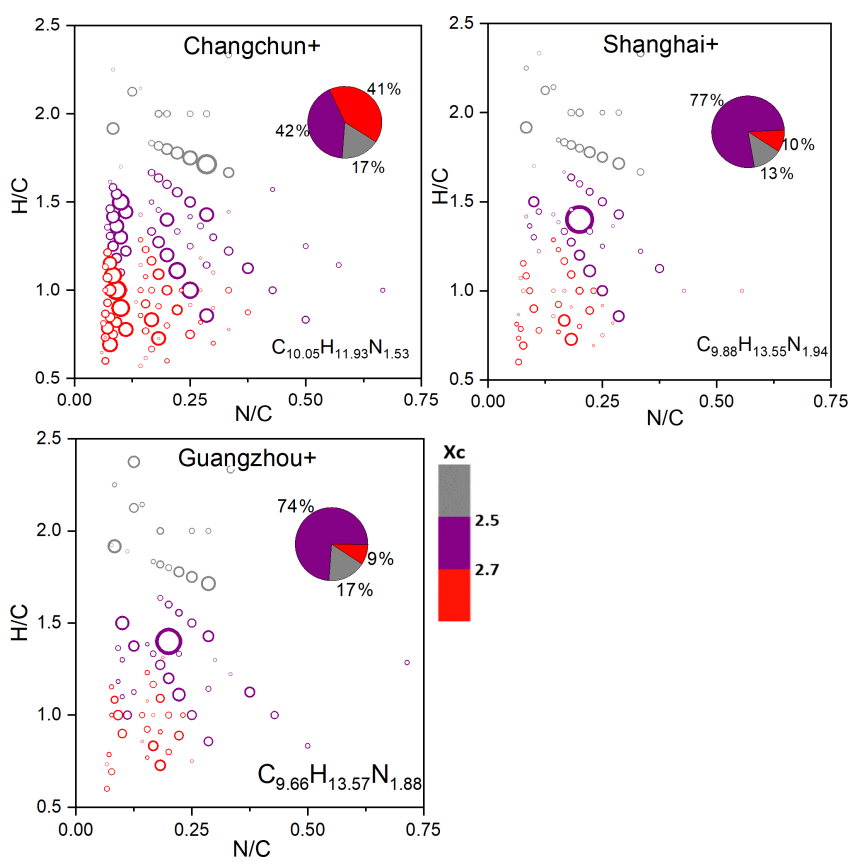

Figure 6. Van Krevelen diagrams for $\mathrm{CHN}+$ compounds in Changchun, Shanghai and Guangzhou samples. The area of circles is proportional to the fourth root of the peak abundance of an individual compound (a diagram with circle areas related to absolute peak abundances is presented in Fig. S10) and the color bar denotes the aromaticity equivalent (gray with $X_{\mathrm{C}}<2.50$, purple with $2.50 \leq X_{\mathrm{C}}<2.70$ and red with $X_{\mathrm{C}} \geq 2.70$ ). The pie charts show the percentage of each $X_{\mathrm{C}}$ category (i.e., gray color-coded compounds, purple color-coded compounds and red color-coded compounds) in each sample in terms of peak abundance.

For example, formulas of $\mathrm{C}_{11} \mathrm{H}_{11} \mathrm{~N}_{1}\left(X_{\mathrm{C}}=2.7\right), \mathrm{C}_{10} \mathrm{H}_{9} \mathrm{~N}_{1}$ $\left(X_{\mathrm{C}}=2.7\right)$ and $\mathrm{C}_{12} \mathrm{H}_{13} \mathrm{~N}_{1}\left(X_{\mathrm{C}}=2.7\right)$, which are assigned to be naphthalene core structure-containing compounds, have relatively higher abundance in Changchun+ than in Shanghait and Guangzhou+. Moreover, the average DBE and $X_{\mathrm{C}}$ values of $\mathrm{CHN}+$ compounds (see Table 1) in Changchun+ are higher than those in Shanghait and Guangzhou+, further indicating that $\mathrm{CHN}+$ compounds in Changchun+ show a higher degree of aromaticity, which can be caused by large coal combustion emissions in the winter in Changchun. Remarkably, as can be seen in Fig. 6, the abundance of $\mathrm{CHN}+$ compounds in Changchun+ distributes evenly among different individual $\mathrm{CHN}+$ compounds, while in Shanghai+ and Guangzhou+ they are dominated by the formula of $\mathrm{C}_{10} \mathrm{H}_{14} \mathrm{~N}_{2}$ (the biggest purple circle in Fig. 6) with a DBE value of 5, which probably has a high concentration and/or high ionization efficiency in the positive ESI mode. According to a previous smog chamber study (Laskin et al., 2010), most $\mathrm{CHN}+$ aromatics are probably generated from biomass burning through the addition of reduced nitrogen (e.g., $\mathrm{NH}_{3}$ ) to the organic molecules via imine formation reaction, indicating that biomass burning probably made a certain contri- 
bution to the formation of $\mathrm{CHN}+$ compounds observed in the three urban OA samples in our study.

\subsection{CHOS- compounds}

In this study, 75-155 CHOS- compounds were observed, accounting for $10 \%, 12 \%$ and $14 \%$ of the total peak abundance of all organics in Changchun-, Shanghai- and Guangzhou-, respectively. Around $89 \%-96 \%$ of these CHOS- compounds were found to fulfill the $\mathrm{O} / \mathrm{S} \geq 4$ criterion allowing the assignment of at least one $-\mathrm{OSO}_{3} \mathrm{H}$ functional group and thus a tentative classification to organosulfates (OSs) (Lin et al., 2012a, b; Tao et al., 2014; Wang et al., 2016, 2017, 2018, 2019a). OSs were shown to affect the surface activity and hygroscopic properties of the aerosol particles, leading to potential impacts on climate (Hansen et al., 2015; Wang et al., 2019a). Out of all formulas, 23 common CHOS- formulas were detected for the three sample locations, accounting for $28 \%, 58 \%$ and $52 \%$ of the CHOSpeak abundance in Changchun-, Shanghai- and Guangzhou, respectively. However, 40 common CHOS- formulas were found between Shanghai- and Guangzhou-, accounting for $60 \%-65 \%$ and $78 \%-81 \%$ in terms of the CHOS- formula numbers and peak abundance, respectively. This indicates that the chemical composition of the major CHOS- compounds of Shanghai- and Guangzhou- are quite similar, while they show substantial chemical differences for samples from Changchun-.

Figure 7 shows the DBEs as a function of carbon number for all CHOS- compounds detected for the three cities. The CHOS- compounds exhibit a DBE range from 0 to 10 and carbon number range of 2-15. However, the majority of CHOS- compounds with elevated peak abundances concentrate in a region with rather low DBE values of $0-5$. The average $\mathrm{H} / \mathrm{C}$ ratios of CHOS- compounds are in the range of 1.56-1.85 and thus higher than for any other compound class, whereas the average DBE values of 1.71-2.55 are the lowest among all classes. This indicates that CHOS- compounds in the OA from the three Chinese cities are characterized by a low degree of unsaturation. Moreover, the pie charts in Fig. 7 show that aliphatic compounds with $X_{\mathrm{C}} \leq 2.5$ are dominant in CHOS- compounds with a fraction of $96 \%-99 \%$ in terms of peak abundance, which is substantially higher than that (13\%-48\%) for $\mathrm{CHO}, \mathrm{CHON}$ and $\mathrm{CHN}$ species. Aliphatic CHOS- compounds with $\mathrm{C} \leq 10$ can be formed from biogenic and/or anthropogenic precursors (Hansen et al., 2014; Glasius et al., 2018; Wang et al., 2019a), such as $\mathrm{C}_{2} \mathrm{H}_{4} \mathrm{O}_{6} \mathrm{~S}_{1}$ (derived from glyoxal) (Lim et al., 2010; McNeill et al., 2012), $\mathrm{C}_{3} \mathrm{H}_{6} \mathrm{O}_{6} \mathrm{~S}_{1}$ (derived from isoprene) (Surratt et al., 2007) and $\mathrm{C}_{8} \mathrm{H}_{16} \mathrm{O}_{4} \mathrm{~S}_{1}$ (derived from $\alpha$-pinene). However, more CHOS- compounds with $\mathrm{C}>10$ and with DBEs lower than 1 are observed in Changchun-, such as $\mathrm{C}_{14} \mathrm{H}_{28} \mathrm{O}_{5} \mathrm{~S}_{1}$, $\mathrm{C}_{13} \mathrm{H}_{26} \mathrm{O}_{5} \mathrm{~S}_{1}, \mathrm{C}_{12} \mathrm{H}_{24} \mathrm{O}_{5} \mathrm{~S}_{1}, \mathrm{C}_{11} \mathrm{H}_{22} \mathrm{O}_{5} \mathrm{~S}_{1}$ and $\mathrm{C}_{11} \mathrm{H}_{20} \mathrm{O}_{6} \mathrm{~S}_{1}$. These high-carbon-number-containing CHOS- compounds are likely formed from long-alkyl-chain compounds with less
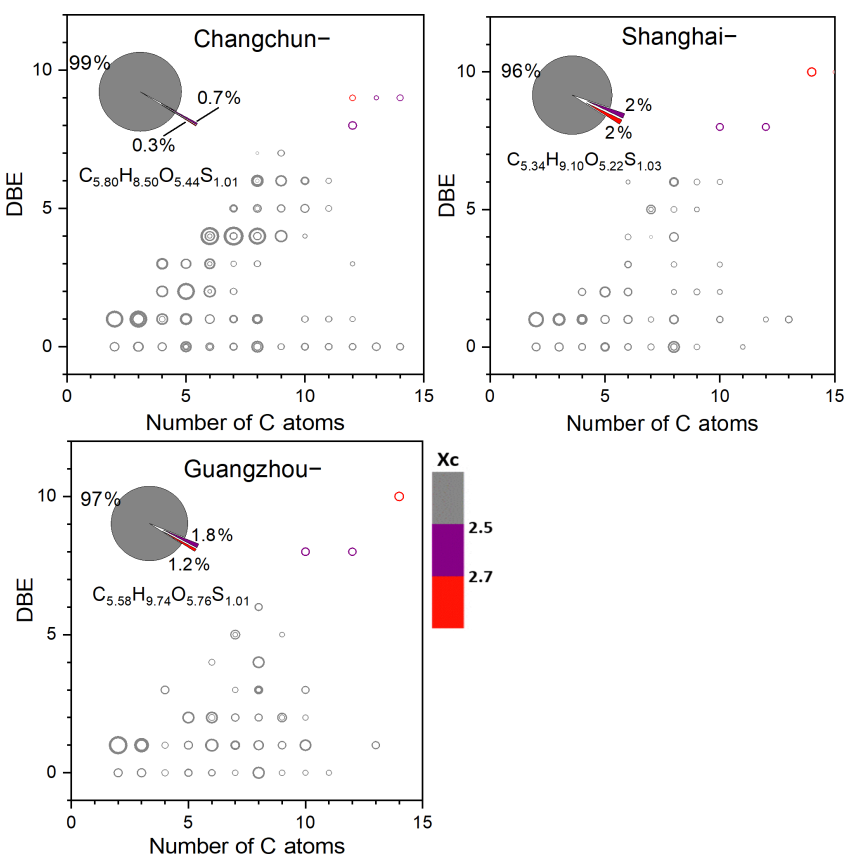

Figure 7. Double bond equivalent (DBE) versus carbon number for all CHOS- compounds for all sample locations. The molecular formula represents the abundance-weighted average CHOS- formula, and the area of circles is proportional to the fourth root of the peak abundance of an individual compound (a diagram with circle areas related to absolute peak abundances is presented in Fig. S11). The color bar denotes the aromaticity equivalent (gray with $X_{\mathrm{C}}<2.50$, purple with $2.50 \leq X_{\mathrm{C}}<2.70$ and red with $X_{\mathrm{C}} \geq 2.70$ ). The pie charts show the percentage of each $X_{\mathrm{C}}$ category (i.e., gray colorcoded compounds, purple color-coded compounds and red colorcoded compounds) in each sample in terms of peak abundance.

oxygenated functional groups, which were previously suggested to be emitted from traffic (Tao et al., 2014) or derived from sesquiterpene emissions (Brüggemann et al., 2019). However, as sesquiterpene emissions can be expected to be very low in wintertime at Changchun, the presence of these compounds further underlines the strong impact of anthropogenic emissions on CHOS- formation in Changchun-. In this study, the $(\mathrm{O}-3 \mathrm{~S}) / \mathrm{C}$ ratio was used instead of the traditional $\mathrm{O} / \mathrm{C}$ ratio to present the oxidation state of $\mathrm{CHOS}$ compounds, since the sulfate functional group contains three more oxygen atoms than common oxygen-containing groups (e.g., hydroxyl and carbonyl), which makes no contribution to the oxidation state of the carbon backbone of the CHOScompounds. Comparing average values for $\mathrm{H} / \mathrm{C},(\mathrm{O}-3 \mathrm{~S}) / \mathrm{C}$ and DBEs of CHOS- for the three sample locations (see Table 1), we find that the $\mathrm{H} / \mathrm{C}$ ratios $(1.85)$ and $(\mathrm{O}-3 \mathrm{~S}) / \mathrm{C}$ ratios (0.61-0.71) for Shanghai- and Guangzhou- samples are larger than those for Changchun- samples $(\mathrm{H} / \mathrm{C}=1.56$ and $(\mathrm{O}-3 \mathrm{~S}) / \mathrm{C}=0.52)$, whereas the $\mathrm{DBE}$ values $(1.71-1.79)$ in Shanghai- and Guangzhou- are lower than those for Changchun- (2.55). These observations indicate that CHOS- 
compounds in urban OA from northeast China are less oxidized but more unsaturated compared to those in east and southeast China, likely due to enhanced emissions from residential heating during winter in north China.

\subsection{CHONS compounds}

A total of $4 \%-5 \%$ of the total organics detected in ESI- were identified as CHONS- compounds in terms of peak abundance. In contrast, CHONS+ compounds account merely for $0.3 \%-1 \%$ of all organics detected in ESI+. The average $\mathrm{MM}_{\text {avg }}$ of the CHONS- compounds for the three sample locations ranges from 214 to $293 \mathrm{Da}$, generally showing larger molecular masses than compounds of any other class because of the likely presence of both nitrate and sulfate functional groups. In total, only five common CHONS- formulas were detected for all three sample locations, accounting for $4 \%, 21 \%$ and $20 \%$ of the CHONS- peak abundance in Changchun-, Shanghai- and Guangzhou-, respectively. As already observed for other compound classes, these percentages imply that the CHONS- compounds in urban OA of Shanghai- and Guangzhou- exhibit a rather similar chemical composition, whereas such compounds are different for Changchun-.

In the OA samples of Shanghai- and Guangzhou-, $78 \%-$ $87 \%$ of CHONS- compounds in terms of peak abundance have seven or more $\mathrm{O}$ atoms in their formulas, allowing the assignment of one $-\mathrm{OSO}_{3} \mathrm{H}$ and one $-\mathrm{NO}_{3}$ functional group in the molecular structures, thus classifying them as potential nitrooxy-organosulfates. In contrast to Shanghai- and Guangzhou-, only $26 \%$ of CHONS- compounds were assigned to such nitrooxy organosulfates for Changchun-, indicating that most of the $\mathrm{N}$ atoms in the CHONS- compounds are present in a reduced oxidation state, e.g., in the form of amines. The average DBE and $X_{\mathrm{C}}$ values of CHONScompounds in Shanghai- and Guangzhou- are 3.3-3.45 and $0.43-0.44$, respectively. Again these values differ for the Changchun- samples with an increased average DBE of 3.75 and an average $X_{\mathrm{C}}$ of 1.06 , indicating that CHONS- compounds in Changchun- possess on average a higher degree of unsaturation and aromaticity compared to such compounds in Shanghai- and Guangzhou- samples. Interestingly, the compound with the formula $\mathrm{C}_{10} \mathrm{H}_{17} \mathrm{O}_{7} \mathrm{NS}$ has the highest relative peak abundance (32\%) in Shanghai- and Guangzhou, whereas in Changchun- the compound with the formula $\mathrm{C}_{2} \mathrm{H}_{3} \mathrm{O}_{4} \mathrm{NS}$ is dominant. $\mathrm{C}_{10} \mathrm{H}_{17} \mathrm{O}_{7} \mathrm{NS}$ has previously been identified as mononitrate organosulfate generated from $\alpha / \beta$ pinene (Iinuma et al., 2007; Surratt et al., 2008; Lin et al., 2012b; Wang et al., 2017), while $\mathrm{C}_{2} \mathrm{H}_{3} \mathrm{O}_{4} \mathrm{NS}$ may be assigned as a cyanogroup-containing sulfate. This observation is comparable to our previous study (Wang et al., 2019a), which found that $\mathrm{C}_{10} \mathrm{H}_{17} \mathrm{O}_{7} \mathrm{NS}$ was dominant for CHONScompounds in low-concentration aerosol samples collected in Beijing (China) and Mainz (Germany). Consistently, a $\mathrm{C}_{2} \mathrm{H}_{3} \mathrm{O}_{4} \mathrm{NS}$ compound had the highest abundance among
CHONS- compounds in polluted Beijing aerosol samples. This agreement can be explained by the adjacent locations of Beijing $\left(39.99^{\circ} \mathrm{N}, 116.39^{\circ} \mathrm{E}\right)$ and Changchun $\left(43.54^{\circ} \mathrm{N}\right.$, $125.13^{\circ} \mathrm{E}$ ) and similar residential heating patterns by coal combustion during wintertime. In conclusion, these results further demonstrate that the precursors for CHONS- compounds in Shanghai- and Guangzhou- are different from those in Changchun-, which is probably due to differences in anthropogenic emissions.

\subsection{Limitations}

In this study, we used the peak abundance-weighted method to illustrate the difference in chemical formulas assigned by the Orbitrap MS. This comparison was made based on the assumption that the measured organic compounds have the same peak abundance response in the mass spectrometer. However, this assumption can bring some uncertainties because the ionization efficiencies vary between different compounds (Schmidt et al., 2006; Leito et al., 2008; Perry et al., 2008; Kruve et al., 2014). For example, the ionization efficiencies of nitrophenol species detected in negative ESI mode can vary by a large degree depending on the position of the substituents at the nitrobenzene ring (Schmidt et al., 2006; Kruve et al., 2014), and the ionization efficiencies of carboxylic acids can also vary by several orders of magnitude depending on the structures (Kruve et al., 2014). Nonetheless, it is a challenging analytical task to identify and quantify all compounds in ambient OA due to the high chemical complexity of OA and the limits in authentic standards of OA. Despite the inherent uncertainties, the peak abundance-weighted comparison of molecular formulas provides an overview of the difference in chemical composition of OA in these three representative Chinese cities. In particular, the chemical formulas assigned in this study can be validated in future studies by authentic standards, and the difference in ionization efficiencies can be further evaluated.

\section{Conclusions}

The molecular composition of the organic fraction of $\mathrm{PM}_{2.5}$ samples collected in three Chinese megacities (Changchun, Shanghai and Guangzhou) was investigated using a UHPLCOrbitrap mass spectrometer. In total, 416-769 (ESI-) and 687-2943 (ESI+) organic compounds were observed and separated into five subgroups: $\mathrm{CHO}, \mathrm{CHN}, \mathrm{CHON}, \mathrm{CHOS}$ and CHONS. Specifically, 120 common formulas were detected in ESI- and 129 common formulas in ESI+ for all sample locations, accounting for $57 \%-71 \%$ and $30 \%-75 \%$ in terms of peak abundance, respectively. Overall, we found that urban OA in Changchun, Shanghai and Guangzhou shows a quite similar chemical composition for organic compounds of high concentrations. The majority of these organic species were assigned to monoaromatic or polyaromatic compounds, 
indicating that anthropogenic emissions are the major source for urban OA in all three cities.

Despite the chemical similarity of the three sample locations for organic compounds in urban OA, remarkable differences were found in chemical composition of the remaining particle constituents, in particular for OA samples from Changchun. In general, a larger number of polyaromatics were observed for Changchun samples, most likely due to emissions from coal combustion during the wintertime residential heating period. Moreover, the peak abundanceweighted average DBE and average $X_{C}$ values of the total organic compounds in Changchun were found to be larger than those for Shanghai and Guangzhou, showing that organic compounds in Changchun possess a higher degree of unsaturation and aromaticity. For average $\mathrm{H} / \mathrm{C}$ and $\mathrm{O} / \mathrm{C}$ ratios a similar trend was observed. While average $\mathrm{H} / \mathrm{C}$ and $\mathrm{O} / \mathrm{C}$ ratios detected in ESI- were found to be highest for Guangzhou samples, relatively lower values were observed for Shanghai and Changchun samples, indicating that OA collected in lower-latitude regions of China experiences more intense photochemical oxidation processes and/or is affected to a larger degree by biogenic sources.

Data availability. All relevant data have been included in this paper in the form of tables and figures. Specific data requests can be addressed by email to the corresponding authors.

Supplement. The supplement related to this article is available online at: https://doi.org/10.5194/acp-21-9089-2021-supplement.

Author contributions. RJH, TH and KW conducted the study design. LY, HN, JG and MW collected the $\mathrm{PM}_{2.5}$ filter samples. KW and $\mathrm{YZ}$ carried out the experimental work and data analysis. KW wrote the manuscript. KW, TH, RJH, MaB, YZ, JH, MB and MG interpreted data and edited the manuscript. All authors commented on and discussed the manuscript.

Competing interests. The authors declare that they have no conflict of interest.

Acknowledgements. This study was supported by the National Natural Science Foundation of China (NSFC, grant nos. 41925015, 91644219 and 41877408), the Chinese Academy of Sciences (nos. ZDBS-LY-DQC001 and XDB40030202), the National Key Research and Development Program of China (no. 2017YFC0212701), and the German Research Foundation (Deutsche Forschungsgemeinschaft, DFG) under grant no. INST 247/664-1 FUGG. Kai Wang and Yun Zhang acknowledge the scholarship from the Chinese Scholarship Council (CSC). Kai Wang acknowledges the scholarship from the Max Plank Graduate Center with Johannes Gutenberg University of Mainz (MPGC) and thanks Ulrich Pöschl, Christopher J. Kampf and Yafang Cheng for their helpful suggestions for this study. Kai Wang also thanks Huanfeng Dong from Zhejiang University for the great support on the programming of data processing.

Financial support. This research has been supported by the National Natural Science Foundation of China (grant nos. 41925015, 91644219 and 41877408), the Chinese Academy of Sciences (grant nos. ZDBS-LY-DQC001 and XDB40030202), the National Key Research and Development Program of China (grant no. 2017YFC0212701), and the Deutsche Forschungsgemeinschaft (grant no. INST 247/664-1 FUGG).

Review statement. This paper was edited by Frank Keutsch and reviewed by three anonymous referees.

\section{References}

An, Z., Huang, R. J., Zhang, R., Tie, X., Li, G., Cao, J., Zhou, W., Shi, Z., Han, Y., Gu, Z., and Ji, Y.: Severe haze in northern China: A synergy of anthropogenic emissions and atmospheric processes, P. Natl. Acad. Sci. USA, 116, 8657-8666, https://doi.org/10.1073/pnas.1900125116, 2019.

Brüggemann, M., Poulain, L., Held, A., Stelzer, T., Zuth, C., Richters, S., Mutzel, A., van Pinxteren, D., Iinuma, Y., Katkevica, S., Rabe, R., Herrmann, H., and Hoffmann, T.: Realtime detection of highly oxidized organosulfates and BSOA marker compounds during the F-BEACh 2014 field study, Atmos. Chem. Phys., 17, 1453-1469, https://doi.org/10.5194/acp17-1453-2017, 2017.

Brüggemann, M., van Pinxteren, D., Wang, Y., Yu, J. Z., and Herrmann, H.: Quantification of known and unknown terpenoid organosulfates in PM10 using untargeted LC-HRMS/MS: contrasting summertime rural Germany and the North China Plain, Environ. Chem., 16, 333-346, https://doi.org/10.1071/EN19089, 2019.

Claeys, M., Graham, B., Vas, G., Wang, W., Vermeylen, R., Pashynska, V., Cafmeyer, J., Guyon, P., Andre, M., Artaxo, P., and Maenhaut, W.: Formation of secondary organic aerosol through photooxidation of isoprene, Science, 303, 1173-1175, https://doi.org/10.1126/science.1092805, 2004.

Daellenbach, K. R., Kourtchev, I., Vogel, A. L., Bruns, E. A., Jiang, J., Petäjä, T., Jaffrezo, J.-L., Aksoyoglu, S., Kalberer, M., Baltensperger, U., El Haddad, I., and Prévôt, A. S. H.: Impact of anthropogenic and biogenic sources on the seasonal variation in the molecular composition of urban organic aerosols: a field and laboratory study using ultra-high-resolution mass spectrometry, Atmos. Chem. Phys., 19, 5973-5991, https://doi.org/10.5194/acp19-5973-2019, 2019.

Ding, X., Zhang, Y.-Q., He, Q.-F., Yu, Q.-Q., Shen, R.-Q., Zhang, Y., Zhang, Z., Lyu, S.-J., Hu, Q.-H., Wang, Y.-S., Li, L.-F., Song, W., and Wang, X.-M.: Spatial and seasonal variations of secondary organic aerosol from terpenoids over China, J. Geophys. Res.-Atoms., 121, 14661-14678, https://doi.org/10.1002/2016JD025467, 2016.

Elzein, A., Dunmore, R. E., Ward, M. W., Hamilton, J. F., and Lewis, A. C.: Variability of polycyclic aromatic hydrocarbons 
and their oxidative derivatives in wintertime Beijing, China, Atmos. Chem. Phys., 19, 8741-8758, https://doi.org/10.5194/acp19-8741-2019, 2019.

Fleming, L. T., Lin, P., Laskin, A., Laskin, J., Weltman, R., Edwards, R. D., Arora, N. K., Yadav, A., Meinardi, S., Blake, D. R., Pillarisetti, A., Smith, K. R., and Nizkorodov, S. A.: Molecular composition of particulate matter emissions from dung and brushwood burning household cookstoves in Haryana, India, Atmos. Chem. Phys., 18, 2461-2480, https://doi.org/10.5194/acp18-2461-2018, 2018.

Fu, P., Kawamura, K., Okuzawa, K., Aggarwal, S. G., Wang, G., Kanaya, Y., and Wang, Z.: Organic molecular compositions and temporal variations of summertime mountain aerosols over Mt. Tai, North China Plain, J. Geophys. Res., 113, D19107, https://doi.org/10.1029/2008JD009900, 2008.

Glasius, M., Hansen, A. M. K., Claeys, M., Henzing, J. S., Jedynska, A. D., Kasper-Giebl, A., Kistler, M., Kristensen, K., Martinsson, J., Maenhaut, W., Nøjgaard, J. K., Spindler, G., Stenström, K. E., Swietlicki, E., Szidat, S., Simpson, D., and Yttri, K. E.: Composition and sources of carbonaceous aerosols in Northern Europe during winter, Atmos. Environ., 173, 127-141, https://doi.org/10.1016/j.atmosenv.2017.11.005, 2018.

Hansen, A. M. K., Kristensen, K., Nguyen, Q. T., Zare, A., Cozzi, F., Nøjgaard, J. K., Skov, H., Brandt, J., Christensen, J. H., Ström, J., Tunved, P., Krejci, R., and Glasius, M.: Organosulfates and organic acids in Arctic aerosols: speciation, annual variation and concentration levels, Atmos. Chem. Phys., 14, 7807-7823, https://doi.org/10.5194/acp-14-7807-2014, 2014.

Hansen, A. M. K., Hong, J., Raatikainen, T., Kristensen, K., Ylisirniö, A., Virtanen, A., Petäjä, T., Glasius, M., and Prisle, N. L.: Hygroscopic properties and cloud condensation nuclei activation of limonene-derived organosulfates and their mixtures with ammonium sulfate, Atmos. Chem. Phys., 15, 14071-14089, https://doi.org/10.5194/acp-15-14071-2015, 2015.

He, X., Huang, X. H. H., Chow, K. S., Wang, Q., Zhang, T., Wu, D., and Yu, J. Z.: Abundance and Sources of Phthalic Acids, Benzene-Tricarboxylic Acids, and Phenolic Acids in $\mathrm{PM}_{2.5}$ at Urban and Suburban Sites in Southern China, ACS Earth Space Chem., 2, 147-158, https://doi.org/10.1021/acsearthspacechem.7b00131, 2018.

Ho, C. S., Lam, C. W. K., Chan, M. H. M., Cheung, R. C. K., Law, L. K., Suen, M. W. M., and Tai, H. L.: Electrospray ionisation mass spectrometry: principles and clinical application, Clin. Biochem. Rev., 24, 3-12, 2003.

Hoffmann, T., Huang, R. J., and Kalberer, M.: Atmospheric analytical chemistry, Anal. Chem., 83, 4649-4664, https://doi.org/10.1021/ac2010718, 2011.

Huang, G., Liu, Y., Shao, M., Li, Y., Chen, Q., Zheng, Y., Wu, Z., Liu, Y., Wu, Y., Hu, M., Li, X., Lu, S., Wang, C., Liu, J., Zheng, M., and Zhu, T.: Potentially Important Contribution of Gas-Phase Oxidation of Naphthalene and Methylnaphthalene to Secondary Organic Aerosol during Haze Events in Beijing, Environ. Sci. Technol., 53, 1235-1244, https://doi.org/10.1021/acs.est.8b04523, 2019.

Huang, R. J., Zhang, Y., Bozzetti, C., Ho, K. F., Cao, J. J., Han, Y., Daellenbach, K. R., Slowik, J. G., Platt, S. M., Canonaco, F., Zotter, P., Wolf, R., Pieber, S. M., Bruns, E. A., Crippa, M., Ciarelli, G., Piazzalunga, A., Schwikowski, M., Abbaszade, G., SchnelleKreis, J., Zimmermann, R., An, Z., Szidat, S., Baltensperger, U.,
El Haddad, I., and Prevot, A. S.: High secondary aerosol contribution to particulate pollution during haze events in China, Nature, 514, 218-222, https://doi.org/10.1038/nature13774, 2014.

Huang, R. J., Cao, J. J., and Worsnop, D.: Sources and Chemical Composition of Particulate Matter During Haze Pollution Events in China, in: Air pollution in Eastern Asia: an integrated perspective, edited by: Bouarar, I., Wang, X. M., and Brasseur, G. P., Springer, Cham, Switzerland, 49-68, 2017.

Iinuma, Y., Müller, C., Berndt, T., Böge, O., Claeys, M., and Herrmann, H.: Evidence for the existence of organosulfates from â-pinene ozonolysis in ambient secondary organic aerosol, Environ. Sci. Technol., 41, 6678-6683, https://doi.org/10.1021/es070938t, 2007.

Jung, J. and Kawamura, K.: Enhanced concentrations of citric acid in spring aerosols collected at the Gosan background site in East Asia, Atmos. Environ., 45, 5266-5272, https://doi.org/10.1016/j.atmosenv.2011.06.065, 2011.

Kautzman, K. E., Surratt, J. D., Chan, M. N., Chan, A. W., Hersey, S. P., Chhabra, P. S., Dalleska, N. F., Wennberg, P. O., Flagan, R. C., and Seinfeld, J. H.: Chemical composition of gas- and aerosol-phase products from photooxidation of naphthalene, J. Phys. Chem. A, 114, 913-934, https://doi.org/10.1021/jp908530s, 2010.

Kind, T. and Fiehn, O.: Seven Golden Rules for heuristic filtering of molecular formulas obtained by accurate mass spectrometry, BMC Bioinformatics, 8, 105, https://doi.org/10.1186/14712105-8-105, 2007.

Kourtchev, I., O’Connor, I. P., Giorio, C., Fuller, S. J., Kristensen, K., Maenhaut, W., Wenger, J. C., Sodeau, J. R., Glasius, M., and Kalberer, M.: Effects of anthropogenic emissions on the molecular composition of urban organic aerosols: An ultrahigh resolution mass spectrometry study, Atmos. Environ., 89, 525-532, https://doi.org/10.1016/j.atmosenv.2014.02.051, 2014.

Kourtchev, I., Godoi, R. H. M., Connors, S., Levine, J. G., Archibald, A. T., Godoi, A. F. L., Paralovo, S. L., Barbosa, C. G. G., Souza, R. A. F., Manzi, A. O., Seco, R., Sjostedt, S., Park, J.H., Guenther, A., Kim, S., Smith, J., Martin, S. T., and Kalberer, M.: Molecular composition of organic aerosols in central Amazonia: an ultra-high-resolution mass spectrometry study, Atmos. Chem. Phys., 16, 11899-11913, https://doi.org/10.5194/acp-1611899-2016, 2016.

Kruve, A., Kaupmees, K., Liigand, J., and Leito, I.: Negative electrospray ionization via deprotonation: predicting the ionization efficiency, Anal. Chem., 86, 4822-4830, https://doi.org/10.1021/ac404066v, 2014.

Laskin, A., Laskin, J., and Nizkorodov, S. A.: Chemistry of atmospheric brown carbon, Chem. Rev., 115, 4335-4382, https://doi.org/10.1021/cr5006167, 2015.

Laskin, J., Laskin, A., Roach, P. J., Slysz, G. W., Anderson, G. A., Nizkorodov, S. A., Bones, D. L., and Nguyen, L. Q.: High-Resolution Desorption Electrospray Ionization Mass Spectrometry for Chemical Characterization of Organic Aerosols, Anal. Chem., 82, 2048-2058, https://doi.org/10.1021/ac902801f, 2010.

Laskin, J., Laskin, A., and Nizkorodov, S. A.: Mass Spectrometry Analysis in Atmospheric Chemistry, Anal. Chem., 90, 166-189, https://doi.org/10.1021/acs.analchem.7b04249, 2018.

Leito, I., Herodes, K., Huopolainen, M., Virro, K., Kunnapas, A., Kruve, A., and Tanner, R.: Towards the electrospray ion- 
ization mass spectrometry ionization efficiency scale of organic compounds, Rapid Commun. Mass Sp., 22, 379-384, https://doi.org/10.1002/rcm.3371, 2008.

Li, Y. J., Huang, D. D., Cheung, H. Y., Lee, A. K. Y., and Chan, C. K.: Aqueous-phase photochemical oxidation and direct photolysis of vanillin - a model compound of methoxy phenols from biomass burning, Atmos. Chem. Phys., 14, 2871-2885, https://doi.org/10.5194/acp-14-2871-2014, 2014.

Lim, Y. B., Tan, Y., Perri, M. J., Seitzinger, S. P., and Turpin, B. J.: Aqueous chemistry and its role in secondary organic aerosol (SOA) formation, Atmos. Chem. Phys., 10, 1052110539, https://doi.org/10.5194/acp-10-10521-2010, 2010.

Lin, P., Rincon, A. G., Kalberer, M., and Yu, J. Z.: Elemental composition of HULIS in the Pearl River Delta Region, China: results inferred from positive and negative electrospray high resolution mass spectrometric data, Environ. Sci. Technol., 46, 7454-7462, https://doi.org/10.1021/es300285d, 2012a.

Lin, P., Yu, J. Z., Engling, G., and Kalberer, M.: Organosulfates in humic-like substance fraction isolated from aerosols at seven locations in East Asia: a study by ultra-high-resolution mass spectrometry, Environ. Sci. Technol., 46, 13118-13127, https://doi.org/10.1021/es303570v, 2012b.

Lin, P., Laskin, J., Nizkorodov, S. A., and Laskin, A.: Revealing Brown Carbon Chromophores Produced in Reactions of Methylglyoxal with Ammonium Sulfate, Environ. Sci. Technol., 49, 14257-14266, https://doi.org/10.1021/acs.est.5b03608, 2015.

McNeill, V. F., Woo, J. L., Kim, D. D., Schwier, A. N., Wannell, N. J., Sumner, A. J., and Barakat, J. M.: Aqueous-phase secondary organic aerosol and organosulfate formation in atmospheric aerosols: a modeling study, Environ. Sci. Technol., 46, 8075-8081, https://doi.org/10.1021/es3002986, 2012.

Ning, C., Gao, Y., Zhang, H., Yu, H., Wang, L., Geng, N., Cao, R., and Chen, J.: Molecular characterization of dissolved organic matters in winter atmospheric fine particulate matters $\left(\mathrm{PM}_{2.5}\right)$ from a coastal city of northeast China, Sci. Total Environ., 689, 312-321, https://doi.org/10.1016/j.scitotenv.2019.06.418, 2019.

Nizkorodov, S. A., Laskin, J., and Laskin, A.: Molecular chemistry of organic aerosols through the application of high resolution mass spectrometry, Phys. Chem. Chem. Phys., 13, 3612-3629, https://doi.org/10.1039/c0cp02032j, 2011.

Noziere, B., Kalberer, M., Claeys, M., Allan, J., D’Anna, B., Decesari, S., Finessi, E., Glasius, M., Grgic, I., Hamilton, J. F., Hoffmann, T., Iinuma, Y., Jaoui, M., Kahnt, A., Kampf, C. J., Kourtchev, I., Maenhaut, W., Marsden, N., Saarikoski, S., Schnelle-Kreis, J., Surratt, J. D., Szidat, S., Szmigielski, R., and Wisthaler, A.: The molecular identification of organic compounds in the atmosphere: state of the art and challenges, Chem. Rev., 115, 3919-3983, https://doi.org/10.1021/cr5003485, 2015.

Pereira, K. L., Hamilton, J. F., Rickard, A. R., Bloss, W. J., Alam, M. S., Camredon, M., Muñoz, A., Vázquez, M., Borrás, E., and Ródenas, M.: Secondary organic aerosol formation and composition from the photo-oxidation of methyl chavicol (estragole), Atmos. Chem. Phys., 14, 5349-5368, https://doi.org/10.5194/acp14-5349-2014, 2014.

Perry, R. H., Cooks, R. G., and Noll, R. J.: Orbitrap mass spectrometry: Instrumentation, ion motion and applications, Mass Spectrom. Rev., 27, 661-699, https://doi.org/10.1002/mas.20186, 2008.
Rincón, A. G., Calvo, A. I., Dietzel, M., and Kalberer, M.: Seasonal differences of urban organic aerosol composition - an ultrahigh resolution mass spectrometry study, Environ. Chem., 9, 298, https://doi.org/10.1071/en12016, 2012.

Riva, M., Tomaz, S., Cui, T., Lin, Y.-H., Perraudin, E., Gold, A., Stone, E. A., Villenave, E., and Surratt, J. D.: Evidence for an Unrecognized Secondary Anthropogenic Source of Organosulfates and Sulfonates: Gas-Phase Oxidation of Polycyclic Aromatic Hydrocarbons in the Presence of Sulfate Aerosol, Environ. Sci. Technol., 49, 6654-6664, https://doi.org/10.1021/acs.est.5b00836, 2015.

Schmidt, A. C., Herzschuh, R., Matysik, F. M., and Engewald, W.: Investigation of the ionisation and fragmentation behaviour of different nitroaromatic compounds occurring as polar metabolites of explosives using electrospray ionisation tandem mass spectrometry, Rapid Commun. Mass Sp., 20, 2293-2302, https://doi.org/10.1002/rcm.2591, 2006.

Shi, Z., Vu, T., Kotthaus, S., Harrison, R. M., Grimmond, S., Yue, S., Zhu, T., Lee, J., Han, Y., Demuzere, M., Dunmore, R. E., Ren, L., Liu, D., Wang, Y., Wild, O., Allan, J., Acton, W. J., Barlow, J., Barratt, B., Beddows, D., Bloss, W. J., Calzolai, G., Carruthers, D., Carslaw, D. C., Chan, Q., Chatzidiakou, L., Chen, Y., Crilley, L., Coe, H., Dai, T., Doherty, R., Duan, F., Fu, P., Ge, B., Ge, M., Guan, D., Hamilton, J. F., He, K., Heal, M., Heard, D., Hewitt, C. N., Hollaway, M., Hu, M., Ji, D., Jiang, X., Jones, R., Kalberer, M., Kelly, F. J., Kramer, L., Langford, B., Lin, C., Lewis, A. C., Li, J., Li, W., Liu, H., Liu, J., Loh, M., Lu, K., Lucarelli, F., Mann, G., McFiggans, G., Miller, M. R., Mills, G., Monk, P., Nemitz, E., O’Connor, F., Ouyang, B., Palmer, P. I., Percival, C., Popoola, O., Reeves, C., Rickard, A. R., Shao, L., Shi, G., Spracklen, D., Stevenson, D., Sun, Y., Sun, Z., Tao, S., Tong, S., Wang, Q., Wang, W., Wang, X., Wang, X., Wang, Z., Wei, L., Whalley, L., Wu, X., Wu, Z., Xie, P., Yang, F., Zhang, Q., Zhang, Y., Zhang, Y., and Zheng, M.: Introduction to the special issue "In-depth study of air pollution sources and processes within Beijing and its surrounding region (APHH-Beijing)", Atmos. Chem. Phys., 19, 7519-7546, https://doi.org/10.5194/acp19-7519-2019, 2019.

Song, J., Li, M., Jiang, B., Wei, S., Fan, X., and Peng, P.: Molecular Characterization of Water-Soluble Humic like Substances in Smoke Particles Emitted from Combustion of Biomass Materials and Coal Using Ultrahigh-Resolution Electrospray Ionization Fourier Transform Ion Cyclotron Resonance Mass Spectrometry, Environ. Sci. Technol., 52, 2575-2585, https://doi.org/10.1021/acs.est.7b06126, 2018.

Sun, Y., Jiang, Q., Zhang, Z., Fu, P., Li, J., Yang, T., and Yin, Y.: Investigation of the sources and evolution processes of severe haze pollution in Beijing in January 2013, J. Geophy. Res.-Atmos., 119, 4380-4389, https://doi.org/10.1002/2014JD021641, 2014.

Surratt, J. D., Gomez-Gonzalez, Y., Chan, A. W., Vermeylen, R., Shahgholl, M., Kleindienst, T. E., Jaoui, M., Maenhaut, W., Claeys, M., Flagan, R. C., and Seinfeld, J. H.: Evidence for Organosulfate in Secondary Organic Aerosol, Environ. Sci. Technol., 41, 517-527, https://doi.org/10.1021/es062081q, 2007.

Surratt, J. D., Gómez-González, Y., Chan, A. W., Vermeylen, R., Shahgholi, M., Kleindienst, T. E., Edney, E. O., Offenberg, J. H., Lewandowski, M., Jaoui, M., Maenhaut, W., Claeys, M., Flagan, R. C., and Seinfeld, J. H.: Organosulfate Formation in Biogenic 
Secondary Organic Aerosol, J. Phys. Chem. A, 112, 8345-8378, 2008.

Tao, S., Lu, X., Levac, N., Bateman, A. P., Nguyen, T. B., Bones, D. L., Nizkorodov, S. A., Laskin, J., Laskin, A., and Yang, X.: Molecular Characterization of Organosulfates in Organic Aerosols from Shanghai and Los Angeles Urban Areas by Nanospray-Desorption Electrospray Ionization High-Resolution Mass Spectrometry, Environ. Sci. Technol., 48, 10993-11001, https://doi.org/10.1021/es5024674, 2014.

Tong, H., Kourtchev, I., Pant, P., Keyte, I. J., O'Connor, I. P., Wenger, J. C., Pope, F. D., Harrison, R. M., and Kalberer, M.: Molecular composition of organic aerosols at urban background and road tunnel sites using ultra-high resolution mass spectrometry, Faraday Discuss., 189, 51-68, https://doi.org/10.1039/c5fd00206k, 2016.

Tong, H., Zhang, Y., Filippi, A., Wang, T., Li, C., Liu, F., Leppla, D., Kourtchev, I., Wang, K., Keskinen, H. M., Levula, J. T., Arangio, A. M., Shen, F., Ditas, F., Martin, S. T., Artaxo, P., Godoi, R. H. M., Yamamoto, C. I., de Souza, R. A. F., Huang, R. J., Berkemeier, T., Wang, Y., Su, H., Cheng, Y., Pope, F. D., Fu, P., Yao, M., Pohlker, C., Petaja, T., Kulmala, M., Andreae, M. O., Shiraiwa, M., Pöschl, U., Hoffmann, T., and Kalberer, M.: Radical Formation by Fine Particulate Matter Associated with Highly Oxygenated Molecules, Environ. Sci. Technol., 53, 12506-12518, https://doi.org/10.1021/acs.est.9b05149, 2019.

Tu, P., Hall, W. A. T., and Johnston, M. V.: Characterization of Highly Oxidized Molecules in Fresh and Aged Biogenic Secondary Organic Aerosol, Anal. Chem., 88, 4495-4501, https://doi.org/10.1021/acs.analchem.6b00378, 2016.

Wang, G., Kawamura, K., Umemoto, N., Xie, M., Hu, S., and Wang, Z.: Water-soluble organic compounds in $\mathrm{PM}_{2.5}$ and sizesegregated aerosols over Mount Tai in North China Plain, J. Geophy. Res., 114, D19208, https://doi.org/10.1029/2008JD011390, 2009.

Wang, K., Zhang, Y., Huang, R.-J., Cao, J., and Hoffmann, T.: UHPLC-Orbitrap mass spectrometric characterization of organic aerosol from a central European city (Mainz, Germany) and a Chinese megacity (Beijing), Atmos. Environ., 189, 22-29, https://doi.org/10.1016/j.atmosenv.2018.06.036, 2018.

Wang, K., Zhang, Y., Huang, R.-J., Wang, M., Ni, H., Kampf, C. J., Cheng, Y., Bilde, M., Glasius, M., and Hoffmann, T.: Molecular characterization and source identification of atmospheric particulate organosulfates using ultrahigh resolution mass spectrometry, Environ. Sci. Technol., 53, 6192-6202, https://doi.org/10.1021/acs.est.9b02628, 2019a.
Wang, M., Huang, R.-J., Cao, J., Dai, W., Zhou, J., Lin, C., Ni, H., Duan, J., Wang, T., Chen, Y., Li, Y., Chen, Q., El Haddad, I., and Hoffmann, T.: Determination of n-alkanes, polycyclic aromatic hydrocarbons and hopanes in atmospheric aerosol: evaluation and comparison of thermal desorption GC-MS and solvent extraction GC-MS approaches, Atmos. Meas. Tech., 12, 47794789, https://doi.org/10.5194/amt-12-4779-2019, 2019b.

Wang, X. K., Rossignol, S., Ma, Y., Yao, L., Wang, M. Y., Chen, J. M., George, C., and Wang, L.: Molecular characterization of atmospheric particulate organosulfates in three megacities at the middle and lower reaches of the Yangtze River, Atmos. Chem. Phys., 16, 2285-2298, https://doi.org/10.5194/acp16-2285-2016, 2016.

Wang, X. K., Hayeck, N., Brüggemann, M., Yao, L., Chen, H. F., Zhang, C., Emmelin, C., Chen, J. M., George, C., and Wang, L.: Chemical characterization of organic aerosol in: A study by Ultrahigh-Performance Liquid Chromatography Coupled with Orbitrap Mass Spectrometry, J. Geophya. Res.-Atmos., 122, 703-722, https://doi.org/10.1002/2017JD026930, 2017.

Xu, W., Sun, Y., Wang, Q., Zhao, J., Wang, J., Ge, X., Xie, C., Zhou, W., Du, W., Li, J., Fu, P., Wang, Z., Worsnop, D. R., and Coe, H.: Changes in Aerosol Chemistry From 2014 to 2016 in Winter in Beijing: Insights From High-Resolution Aerosol Mass Spectrometry, J. Geophys. Res.-Atmos., 124, 1132-1147, https://doi.org/10.1029/2018jd029245, 2019.

Yang, X. J., Qu, Y., Yuan, Q., Wan, P., Du, Z., Chen, D., and Wong, C.: Effect of ammonium on liquid- and gas-phase protonation and deprotonation in electrospray ionization mass spectrometry, Analyst, 138, 659-665, https://doi.org/10.1039/C2AN36022E, 2013.

Yassine, M. M., Harir, M., Dabek-Zlotorzynska, E., and SchmittKopplin, P.: Structural characterization of organic aerosol using Fourier transform ion cyclotron resonance mass spectrometry: aromaticity equivalent approach, Rapid Commun. Mass Sp., 28, 2445-2454, https://doi.org/10.1002/rcm.7038, 2014.

Zhang, P.: Revitalizing old industrial base of Northeast China: Process, policy and challenge, Chin. Geogra. Sci., 18, 109-118, https://doi.org/10.1007/s11769-008-0109-2, 2008.

Zielinski, A. T., Kourtchev, I., Bortolini, C., Fuller, S. J., Giorio, C., Popoola, O. A. M., Bogialli, S., Tapparo, A., Jones, R. L., and Kalberer, M.: A new processing scheme for ultra-high resolution direct infusion mass spectrometry data, Atmos. Environ., 178, 129-139, https://doi.org/10.1016/j.atmosenv.2018.01.034, 2018. 